\title{
C. el Centralismo EN LA NUEVA CONSTItUCIÓN POLÍTICA COLOMBIANA
}

\author{
SANDRA MORELLI \\ Profesora Universidad Externado de Colombia \\ y \\ JAIME ORLANDO SANTOFIMIO \\ Profesor Universidad Externado de Colombia
}


SUMARIO

Introducción.-1. El problema de la forma de Estado en ColomBIA.-II. LA AUTONOMIA EN EL ACTUAL ORDENAMIENTO CONSTITUCIONAL.-1. Gobernarse por autoridades propias. 1.1. Origen electoral de las autoridades departamentales. 1.2. Origen electivo de las autoridades municipales. 1.3. Consecuencia de la elección popular de las autoridades departamentales y municipales. 2. Ejercer las competencias que le correspondan. 3. Administrar sus recursos y establecer los tributos necesarios para el cumplimiento de sus funciones. 3.1. El manejo presupuestal y la Hacienda pública. 3.2. Planeación y presupuesto. 3.3. Autonomía para establecer los tributos necesarios para el cumplimiento de sus funciones. 3.4. Control de la gestión fiscal en las entidades territoriales. 3.5. Emisión de títulos y bónos de deuda pública. 4. Participar en las rentas nacionales. 5. Otras materias objeto de monopolio del Estado central. III. REELABORACIÓN DEL ESQUEMA DESCENTRALISTA: EL DEPARTAMENTO, NUEVO CENTRO DE PODER.-1. Antecedentes históricos. 2. Los departamentos en el actual ordenamiento jurídico. 3. El gobernador. 4. Relaciones del departamento y el municipio. IV. EL PAPEL DEL MUNICIPIO COLOMBIANO.-1. Antecedentes históricos. 2. El municipio en el nuevo ordenamiento territorial. 3. Comunas y corregimientos. 4. Categorización de municipios y asociaciones. V. LOS DISTRITOS.-VI. LAS AREAS METROPOLITANAS. -VII. LAS PROVINCIAS.-1. Breves antecedentes históricos. 2. La provincia en la Constitución de 1991. VIII. TerRIToRIOS IndGenas.-1. Minorías y Estado pluralista. 2. El Estado pluralista en el texto constitucional de 1991 y los territorios indigenas. IX. LAS REGIONES.-1. El Estado regional: verdadero significado. 2. Tipos de regionalismo. 3. La región en la Constitución colombiana. 


\title{
C. EL CENTRALISMO EN LA NUEVA CONSTITUCIÓN POLITICA COLOMBIANA
}

\author{
POR \\ SANDRA MORELLI \\ Profesora Universidad Externado de Colombia \\ y \\ JAIME ORLANDO SANTOFIMIO \\ Profesor Universidad Externado de Colombia
}

INTRODUCCION

Indudablemente el «ideal» del Estado se articula alrededor de una nación plenamente configurada. En efecto, en tales circunstancias la estabilidad de las instituciones politicas es más fácilmente sostenible, y estructuras jurídicas homogéneas, son relativamente aceptables.

Sin embargo, a pesar de ser posible reconocer una amalgama, relativamente sólida entre la población de un pais, se hace menester distribuir adecuadamente el poder político y la administración. Tal distribución tiene por objeto privilegiar el principio democrático de la participación, y los valores de eficiencia y eficacia en la prestación de los servicios.

Pero el problema de acortar las distancias entre la burocracia y los gobernados se hace un imperativo más latente en los Estados multinacionales, o en aquéllos donde los factores de identidad nacional no son lo suficientemente fusionantes o coexisten al lado de grupos minoritarios.

El problema de la organización del poder del Estado en el ámbito 
territorial se enfrenta, invariablemente, a la necesidad de conciliar dos tipos de fuerzas, las centripetas y las centrifugas aparentemente antagónicas entre sí.

Las primeras presentan un carácter prevalentemente centralizante, las segundas descentralizador ${ }^{1}$.

En todo caso, de lo que se trata es de hallar un punto de equilibrio, donde sin sacrificar la unidad de la soberania internacional, las entidades territoriales puedan gozar de un conjunto de atribuciones y funciones, ejercidas de manera autárquica y autónoma; que les permitan conservar su identidad cultural y contribuir al desarrollo nacional.

Sin embargo, la historia institucional de los Estados pone en evidencia que encontrar aquel punto de equilibrio no es tarea fácil, entre otras razones, porque cualquier solución que se adopte comporta sacrificar un determinado grupo de intereses para privilegiar otros.

A manera de ejemplo podemos recordar varios casos en Europa: Irlanda, luego varias insurgencias frente al Estado británico, logró finalmente que se le reconociera una especie de autonomía denominada home rule.

El profesor Roberto RUFFILLI ${ }^{2}$, da cuenta de cómo el proceso de unificación del Estado italiano fue puesto en tela de juicio, porque -entre otras-comportaba un monopolio jurídico y político por parte de Roma. Las soluciones planteadas fueron, o el retorno al pasado preunitario, o la instauración de un régimen federal. Las dos alternativas pretendian darle un lugar privilegiado al pluralismo, como principio rector de la organización de la sociedad.

Este proceso, fue paralelo tanto a la lucha por fortalecer la sociedad civil a través de una redistribución del poder, como a la batalla contra la centralización administrativa ${ }^{3}$.

1 No siempre las fuerzas centrifugas se identifican con el interés local y las centripetas con el interés nacional o general. La experiencia histórica tiende a demostrar que una excesiva centralización, con miras a tutelar la unidad nacional, puede generar efectos perversos. En efecto, en tal caso se acentúan las distancias entre la Administración y los administrados, lo que genera movimientos separatistas, éstos sí fuente de desintegración del Estado. A manera de ejemplo podemos citar España franquista, Yugoslavia o la URSS.

Dentro de esta filosofía resulta sugestivo el título que le da Giuliano Amato a un artículo reciente en la revista Regioni e governo locale, gennaio-febbraio 1991, "Proposte per un nuovo stato regionale", Rimini, Maggioli editore: L'autonomia rafforza l'unità nazionale.

2 Profesor de la Universidad de Bologna y víctima reciente de las Brigadas Rojas, movimiento terrorista italiano.

3 En Mateucci Nicola et alii: L'organizzazione della politica. Cultura, istituzioni, partiti nell'Europa liberale, pp. 429 y ss., II Mulino, Bologna 1988. Allí se explica cómo 

liberal.

Este tipo de reivindicaciones tendió a generalizarse en toda Europa

Francia, también se debatió entre el centralismo y la descentralización. Del Antiguo Régimen, caracterizado por una real desarticulación de los poderes locales respecto del central - sin que la corona renunciara a la pretensión de unificar la nación, tarea en la cual ocupó un lugar preponderante la figura del intendente-, se pasa al régimen postrevolucionario que reconoce, en medida muy contenida, la existencia del pouvoir municipal.

Posteriormente se perfila el Estado francés, como paradigma de centralización con la reestructuración administrativa de Napoleón, implementada a partir del año VIII ${ }^{4}$.

En consecuencia, se desarrollan corrientes que pretenden revitalizar la vida de las entidades locales y denuncian abiertamente la centralización de Paris. Dentro de las varias tendencias doctrinarias es de destacar el nombre del ya clásico Benjamin Constant ${ }^{5}$.

Pero el conflicto no culmina en el siglo pasado; Francia se caracteriza por su tradición centralista, aunque de reciente, a partir de 1982, haya implementado importantes reformas en materia de descentralización del Estado.

\section{EL PROBLEMA DE LA FORMA DE ESTADO EN COLOMBIA}

También en Colombia, el péndulo ha oscilado de un lado al otro, alternando soluciones centralistas con federales.

el Estado unitario se consideró como una imposición de la clase dominante y la libertad local como una "garantía individual. Las demandas de autonomia pretendian combinar los principios de libertad del Estado con la libertad en el Estado. Se recuerda entre otros el nombre de Minghetti como abanderado de la descentralización. Este movimiento fue por lo demás paralelo al desarrollo del sufragio universal.

4 Este acaecimiento permitió a Tocqueville afirmar que no existió solución de continuidad entre l'Ancien Régime y la Revolución Francesa.

5 Jean-Louis MESTRE en "L'organizzazione della politica...", op. cit. Sobre el particular consúltese además Luciano Vandelli: Poteri Locali. Le origini nella Francia Rivoluzionaria, le prospective nell'Europa delle Regini, II Mulino, Bologna 1990; Sandra MoRELLI: La revolución francesa y la administración territorial en Colombia. Perspectivas comparadas, Universidad Externado de Columbia, Bogotá 1991; Françoise LuCHAIRE et alii: Le droit de la décentralisation, Presses Universitaires de France, Paris 1983; Eduardo GaRCIA DE EnTERRIA: Revolución Francesa y administración contemporánea, Taurus, Madrid 1981. 
Asi, regimenes constitucionales como los existentes en 1821, 1830 , 1832 y 1843, montaron toda su teorética administrativa sobre un excesivo centralismo, considerado como pilar de la unidad estatal. Se trataba de ahogar los impulsos autonómicos, ignorando las peculiaridades objetivas de las distintas comunidades residentes en las regiones geográficas del pais, peculiaridades que por lo demás, habian sido estimuladas durante el periodo colonial ${ }^{6}$.

Las Constituciones de 1853, 1858 y 1863 generaron procesos contrarios. Pretendieron durante su corta vigencia, promover el impulso de la vida local mediante el reconocimiento de una amplia esfera de potestades y competencias a las entidades territoriales, provincias o estados según el caso ${ }^{7}$. En un primer momento a las provincias se les reconoció el poder municipal en toda su amplitud y paralelamente las competencias del Estado se fijaron de manera taxativa, tal como se lee en el artículo 10 de la Constitución politicá de 1853.

Dentro de la misma concepción ideológica, en los ordenamientos fundamentales de 1858 y 1863, se instituyeron los Estados en el ámbito de una organización federal. En efecto, se les reconoció «soberanía» 8 para gobernarse libremente en todos aquellos asuntos cuyo manejo no fuese atribuido de manera expresa al gobierno federal -cláusula de los poderes residuales, artículo 12 de la Constitución de 1863-. Sin embargo los Estados miembros de la federación, tendieron a sacrificar en gran medida la verdadera dimensión de la filosofía del pouvoir municipal ${ }^{9}$.

Los sucesos políticos de 1885 dan al traste con este interesante momento autonomista. La estructura federal desaparece para dar paso a un

6 Al respecto son pertinentes las interesantes apreciaciones sobre el proceso de autonomia durante la colonia e independencia, expuestas por José Maria OTS CAPDEQUI en El estado español en las Indias, pp. 182 y ss., Fondo de Cultura Económica, México 1986. Del efecto dispersante de la colonia da cuenta el profesor Carlos RESTREPO PIEDRAHITA: "La técnica de dominación - que no de gobierno-, de la monarquía absolutista peninsular consistió fundamentalmente en la explotación económica de sus territorios y súbditos de ultramar por medio de agentes subalternos civiles, militares y eclesiásticos.

"No le importaba, no estaba en su interés, por contraproducente con los objetivos de la dominación, la educación cultural y menos la cívica -es decir, política- de los nativos. Como tampoco les convenia estimular entre ellos y las respectivas regiones el espíritu de identidad y solidaridad. Toda politica de dominación colonialista supone el fomento y mantenimiento de la dispersión, de la separación, de la incoherencias, en Constituciones de la primera República liberal, tomo III, p. 29, Universidad Externado de Colombia, Bogotá, Colombia 1985. (Las negritas son nuestras.)

7 Manuel Murillo Toro, fue en la época, un importante impulsor de estas ideas, como se desprende del análisis de todos aquellos proyectos que presentó, tendentes a reformar el Estado colombiano.

8 Se disiente de aquella corriente doctrinaria que considera a los Estados miembros de una federación como titulares de soberanía, cuando en realidad ésta concierne tan sólo al Estado federal, quien la ejerce tanto a nivel interno como internacional. No es soberano un ente que no es sujeto de derecho internacional.

- Véase Sandra MoRelli: La Revolución, op cit., pp. 209-221. 
Estado reconstruido en forma de república unitaria, con todas las transformaciones y consecuencias que dicha opción política implica.

Como lo señaló en su oportunidad, uno de los defensores del nuevo orden: «... la Constitución del 5 de agosto de 1886, al proclamar la república unitaria, en su artículo $1 .^{\circ}$, declaró expresamente la unidad de la nación, y por lo tanto de su soberanía y del gobierno que de ésta emanaba» ${ }^{10}$.

Las razones históricas esgrimidas por el constituyente Samper hubiesen sido válidas si la unidad del Estado colombiano se hubiese fracturado. Lo cierto es que nuestro federalismo nunca pretendió tal objetivo. Persiguió ante todo racionalizar la distribución de funciones, competencias y servicios en todo el territorio nacional, y procurar la participación ciudadana. Es oportuno recordar que la filosofía del Estado federal consiste en hacer posible la coexistencia de las distintas comunidades que integran así una sociedad pluralista, donde los intereses locales asuman su verdadera dimensión en la fórmula federal. El texto del 86, por el contrario, supuso que la unidad se lograba a través del totalitarismo del Estado y de la sumisión, por no decir anulación de la autonomia local.

Largo tiempo tuvo que transcurrir para que, finalmente, en la década de los ochenta se moldearan importantes mecanismos de descentralización. Dentro de las reformas institucionales adoptadas es de destacar la elección popular de alcaldes.

\section{LA AUTONOMIA EN EL ACTUAL ORDENAMIENTO CONSTITUCIONAL}

"Colombia es un Estado social de derecho, organizado en forma de República unitaria, descentralizada, con autonomía de sus entidades terri-

10 José María SAmper: Derecho público interno de Colombia, tomo II, pp. 25-26, Biblioteca Banco Popular, Bogotá, 1974. Y agregaba: «... con el artículo primero Colombia ha vuelto a la verdad de las cosas, según la historia y su modo de ser. Ella antes de 1861, tuvo unidad política y social, como la había tenido durante el régimen de la conquista española y la colonia...”. Independientemente de que tan respetable jurista ignore la ausencia de unidad nacional -entendida la nación en términos sociológicos-, que caracterizó nuestro País no sólo durante la colonia sino en el siglo pasado, es de llamar la atención sobre el argumento justificativo de cual él se sirve: la historia. Este tipo de razonamiento tiende a justificar el statu quo porque siempre ha sido así. Dice Manuel GARCIA PELAYO al respecto: «El concepto histórico tradicional surge en su formulación consciente como actitud polémica frente al concepto racional, o, dicho de un modo más preciso, como ideología del conservatismo frente al liberalismo. El revolucionario mira al futuro y cree en la posibilidad de conformarlo; el conservador mira al pasado y tiende a considerarlo como un orden inmutable", en Derecho constitucional comparado, p. 41, Alianza Editorial, Madrid 1987. 
toriales...", se lee en el artículo $1 .^{\circ}$ del nuevo texto constitucional. Esta norma debería encontrar pleno desarrollo a lo largo de todo el texto y especialmente en los títulós XI y XII.

Sin embargo, de un análisis detallado se desprende, que los resultados obtenidos son bien distintos. En realidad se reproduce la esencia de la ya más que centenaria fórmula de centralización política y descentralización administrativa.

Un tal sistema de articulación del poder en el ámbito territorial comporta que la decisión política y el derecho sean monopolio del Estado central, del Congreso -en el mejor de los casos- o del Gobierno; en consecuencia, se excluye cualquier fuente alternativa de producción del derecho y las instancias locales aparecen tan sólo como instrumentos neutrales del poder central.

De la descentralización administrativa, como bandera de la Europa liberal durante el siglo pasado, da cuenta el profesor Roberto RUFFILLI, quien respecto del caso italiano, subraya las negativas consecuencias, consistentes en catalogar al poder local como neutral, como instrumento administrador, ausente del proceso político decisional, cuyo monopolio corresponde tan sólo a instancias superiores ${ }^{11}$.

Dentro del mismo paradigma - centralización política y descentralización administrativa-, parece mantenerse el actual ordenamiento territorial colombiano a pesar de que el artículo 287 del texto constitucional estatuya: «Las entidades territoriales gozan de autonomía para la gestión de sus intereses...».

El verdadero alcance etimológico de la palabra autonomía es la potestad del ente calificado como autónomo de darse sus propias normas. Se trata entonces de una potestad eminentemente política, que no se concreta, tan sólo, en la toma de decisiones politicas, sino que además lleva insita la facultad de elegir sus propias autoridades.

Para ampliar la noción resultan ilustrativas las consideraciones de ZANOBINI, que define el concepto como «la facultad que tienen algunas asociaciones de organizarse jurídicamente, de crear un derecho propio, derecho que no sólo es reconocido como tal por el Estado, sino que lo incorpora a su propio ordenamiento jurídico y lo declara obligatorio, como las demás leyes y reglamentos». Agrega FERRANDO BADIA: «... la esencia de la autonomía - radica - en la Facultad que tiene una entidad pública de darse leyes en sentido material (que son diversas de las simples normas jurídicas) destinadas a formar parte del ordenamiento jurídico es- 
tatal». Y prosigue: «... la autonomía implica siempre competencias legislativas» ${ }^{12}$.

Pero ninguna de las entidades territoriales ya existentes o por integrar, contenidas en el texto constitucional son en estricto sentido, titulares de autonomia; en otros términos, ni el departamento, ni el municipio, y tanto menos la provincia o la región, gozan de potestad legislativa. En armonía con las construcciones doctrinarias es posible afirmar que el nuevo texto denomina autonomía lo que en realidad es autarquía.

Esta última noción la define el ya citado ZANOBINI, como la facultad jurídica de un ente que opera por sí mismo para la consecución de determinados fines, mediante el desplegar de actividades administrativas. FERRANDO BADIA completa la idea al afirmar que la autarquía es una especie de descentralización administrativa ${ }^{13}$.

Tal vez es pertinente aclarar que por la naturaleza misma de las cosas, siempre la autonomía comporta autarquía. En efecto, en la Declaración Universal Sobre Autonomía Local (IULA) de 1985 se dispone: «La autonomia municipal significa el derecho y la responsabilidad de los gobiernos locales para regular y administrar los asuntos públicos en régimen de propias responsabilidades y en interés de la población local...". Dentro de la misma lógica la Constitución italiana reconoce autarquía a las regiones, sobre las mismas materias respecto de las cuales ellas gozan de autonomía, es decir, de potestad legislativa -artículos 117-118.

Del análisis que a continuación emprendemos, parece derivar entonces, que el constituyente colombiano incurrió en una imprecisión terminológica, puesto que en realidad su móvil no era instituir un Estado autonómico, mas sí un Estado autárquico. Nos encontramos, por tanto, ante un claro y típico ejemplo de Estado unitario, descentralizado. Asi, el desarrollo de aspectos fundamentales para la vida local permanecen en el nivel central y se le atribuyen al legislador único, dentro de un incongruente proceso acumulativo de funciones, que por su naturaleza entran dentro de la categoria de intereses propios del nivel periférico.

El articulo 287 dispone que la autonomía debe ejercerse dentro de los parámetros legales, sin que se imponga ningún límite específico; al ejercicio de la potestad legislativa. En realidad el monopolio de la ley,

12 En FERRANdo Badia: El estado unitario, el federal y el autonómico, p. 175, editorial Tecnos, Madrid 1985. No sobran otras consideraciones del autor en materia: "Ser entidades autónomas no supone que sean soberanas, sino que presupone su integración en el Estado. De ahí que la actividad legislativa de los entes autónomos ha de estar de acuerdo con los principios de integración del Estado de que forma parte. La autonomia es en efecto, libertad, facultad de promulgar normas, pero con coordinación necesaria respecto de una colectividad más grande.»

13 En ibidem, p. 175. 
por disposición del constituyente, abarca un amplio abanico de intereses propios de las entidades locales, cuya legislación habría podido atribuirse al nivel periférico sin que con esto se menoscabara la unidad del Estado colombiano.

Pero analicemos el verdadero alcance del ya citado artículo 287. Alli se establece que los derechos que derivan de la autonomía son:

1. Gobernarse por autoridades propias.

2. Ejercer las competencias que les corresponden.

3. Administrar los recursos y establecer los tributos necesarios para el cumplimiento de sus funciones.

4. Participar en las rentas nacionales.

\section{Gobernarse por autoridades propias}

En su sentido genuino, esta disposición hace referencia a la potestad de las entidades locales de decidir quién ha de gobernarlas. Tal elección se hace a través del ejercicio del derecho al voto.

No está de más recordar que la posibilidad de elegir autoridades propias tiene íntima relación con la definición de las entidades territoriales como tales, y no como simples circunscripciones para la administración del Estado.

Dentro de la dimensión política que se le reconoce a las entidades territoriales, debe resaltarse la institución de mecanismos de participación al servicio de la población local -artículos 40, 103 numeral 3-. Sin embargo, no se entiende por qué se dejan tales aspectos al monopolio del legislador ${ }^{14}$.

14. En Italia, el 8 de junio de 1990 , se aprobó la ley 142 sobre ordenamiento de las autonomías locales. Uno de sus aspectos innovadores fue el reconocimiento de la potestad estatutaria a los comunes. Este tipo de reforma permitirá, una reorganización de las entidades locales fundada sobre la diferenciación objetiva, de éstas entre sí. Pero lo que nos interesa destacar es que entre las varias materias objeto de regulación, no regional, sino municipal se encuentra la participación popular. En Luciano VANDELLI: Ordinamento delle autonomie locali, p. 36, Maggioli editore, Rimini 1990. 


\subsection{Origen electoral de las autoridades departamentales}

A nivel departamental, los diputados de la asamblea se eligen popularmente, lo que es ya una tradición arraigada en nuestra cultura juridica y política: la base electoral de las corporaciones públicas. Su número no podrá ser inferior a 11 miembros, ni superior a 31 .

Por tanto, la innovación más importante al régimen departamental, es la introducción de la elección popular de gobernadores. El período establecido será de tres años.

Pero, ¿cuál es la naturaleza jurídica del gobernador? A tenor del artículo 303 del texto analizado, se trata del jefe de la administración seccional y representante legal del departamento, lo que está en plena armonia con su carácter de órgano elegido popularmente. No obstante, en el artículo antes citado se lee que éste será agente del Presidente de la República para el mantenimiento del orden público y para la ejecución de la política económica general, «asi como para aquellos asuntos que mediante convenios la nación acuerde con el departamento".

Tal disposición concuerda con el artículo 115 donde se lee: «... Las gobernaciones... forman parte de la rama ejecutiva", pero una cosa es tener funciones ejecutivas y otra es pertenecer a la rama ejecutiva central.

En otros términos, el gobernador a pesar de ser elegido por los ciudadanos del departamento continúa como agente del poder ejecutivo. Se trata de una simbiosis poco saludable para un régimen que pretende aparecer como autonómico.

Para fundar estas observaciones no están de más algunas consideraciones sobre el origen histórico y conceptual de la institución.

La figura del gobernador, en el régimen francés - hoy denominado prefecto- tiene raices en el intendente del Ancien Régime. Se trataba de un órgano, designado por el rey, que dentro de una lógica centralizante del sistema, debia contribuir a afianzar la unidad nacional ${ }^{15}$. La Revolución retomó la figura bajo el nombre de procurador, concebida como instancia de articulación del poder estatal con el poder municipal; eslabón, pues, de la pirámide administrativa, eminentemente centralizante. No olvidemos que se hace referencia a un agente del poder central, que tutela los intereses de la nación, como acertadamente lo entendió Napöleón.

Rápidamente el cuerpo de los prefectos se empezó a caracterizar

15 Hervé DETTON et alii: “L'ancêtre de notre préfet actuel», en Administration rêgional et local de la France, p. 11, Presses Universitaires de France, Paris 1968. 
por su alto grado de profesionalidad, constituyéndose en el primer antecedente de una organización burocrática. En efecto, por primera vez es reconocible el fenómeno de un staff que permanece en su cargo, independientemente de los intereses políticos del gobierno, porque posee el kwo how ${ }^{16}$.

Una vez adquirido, por parte del departamento francés, el rango de ente territorial -en un primer momento era tan sólo circunscripción para la administración del Estado-, el prefecto recibe una doble investidura, como representante del poder central y como suprema autoridad administrativa de la misma entidad.

Con tal perfil permanece prácticamente inmodificado, hasta 1982, cuando los poderes del ejecutivo departamental se transfieren del Prefecto al Presidente del consejo departamental. El primero conserva sólo su carácter de funcionario de la Administración central y es por ésta designado. El segundo, por el contrario, cuenta con legitimidad popular puesto que es elegido por el mismo consejo.

De tal manera que paralelamente a exigencias de democratización del sistema, se opta por una bifurcación de la figura. En efecto, no parece razonable que en un mismo órgano se concentre la función de tutelar el interés nacional y, al mismo tiempo, el local, puesto que aunque no necesariamente éstos tengan que entrar en conflicto, sí son, en todo caso, distintos.

La solución francesa del 82 , por lo demás, no fue original; se limitó a recoger la experiencia de otros paises como Italia, con mayor tradición en materia de autonomía.

El constituyente colombiano, por el contrario, optó por conjugar en una sola persona dos investiduras distintas, sin evaluar las consecuencias, que desde ya podemos afirmar que no serán positivas, para el interés departamental.

No se quiere desconocer con estas aseveraciones que existe una necesidad de coordinación indispensable en todo Estado, no sólo en el unitario, sino incluso en el federal; necesidades que se hacen más latentes en materia relativas al orden público o económicas. Sin embargo, olvidó el constituyente que manteniendo el carácter del gobernador como agente del Presidente y vinculando las gobernaciones a la estructura del poder ejecutivo central, lograría mermar mínimamente nuestra tradición centralizante y piramidal.

16 Luciano Vandelli: Poteri locali.., op. cit., p. 30; Yann Fauchois: Dizionario critico della Rivoluzione Francese, p. 591, Bompiani editore, Milano 1988. 


\subsection{Origen electivo de las autoridades municipales}

A nivel municipal, se ratifica el origen electoral de sus autoridades, concejales y alcaldes.

Ya desde la reforma constitucional de 1986, el alcalde colombiano había perdido su carácter de agente del Gobierno central. En el texto constitucional hoy vigente se lee que será jefe de la administración local y representante local del municipio.

1.3. Consecuencia de la elección popular de las autoridades departamentales y municipales

En todo caso no se debe olvidar que la elección popular de las autoridades debe comportar, y he ahí su real envergadura, la titularidad de atribuciones políticas. Así las cosas, se implanta un régimen de autonomías. Pero del examen de los artículos relativos a las atribuciones y competencias de los órganos departamentales y municipales, se desprende que a éstos se les atribuyen funciones eminentemente administrativas como se analizará oportunamente.

La única consecuencia política importante de la elección popular de gobernadores es la institucionalización del voto programático contenido en el artículo 259 del texto constitucional.

La sujeción del gobernador al poder central encuentra además un notable reforzamiento en aquella norma que establece que éste podrá ser suspendido o destituido de su cargo, por el Presidente de la República -artículo 304.

Y en el artículo 314, inc. 2 se lee: «El Presidente y los gobernadores, en los casos taxativamente señalados por la ley, suspenderán o destituirán a los alcades».

\section{Ejercer las competencias que le correspondan}

La potestad de ejercer las competencias correspondientes, atribuida a las entidades territoriales, deriva precisamente de esta calidad. En efecto, como circunscripciones para la administración del Estado carecen de autonomía. 
Se trata, en todo caso, de una atribución eminentemente administrativa, de ejecución de la Constitución o la ley. En realidad todo el régimen de competencias de las entidades locales ha sido ya establecido a nivel constitucional, o será objeto de desarrollo de la legal —artículo 288.

El sistema de competencias ha de ser promulgado a través de la ley orgánica de ordenamiento territorial; a la ley ordinaria corresponderá, según el artículo 356, la fijación de los servicios públicos a cargo de las entidades territoriales. En este sentido, se observa una clara discrepancia conceptual entre el régimen jurídico de las competencias y el de los servicios, lo que generará problemas indubitables de interpretación constitucional que habrán de ser dilucidados por las autoridades competentes.

Vale la pena advertir, que mientras estos ordenamientos legales no se promulguen, las actuales entidades deberán continuar aplicando las normas vigentes sobre la materia, siempre y cuando no sean contrarias al nuevo texto constitucional.

El artículo 150 numeral 4, le atribuye al Congreso la función de definir, a través de la ley, las competencias de las entidades territoriales. Por lo demás, se trata de una ley orgánica, según lo establece el artículo 151. Asimismo, el artículo 356 dispone que la ley, a iniciativa del Gobierno, fijará los servicios a cargo de la nación y de las entidades territoriales.

Se excluye toda técnica de repartición de competencias, fundada en el residuo de competencias, a partir de la categoría de intereses propios de la respectiva entidad territorial. Esta lógica es apreciable en el sistema de administración local francés, donde a pesar de su paradigmático centralismo, se hace conciencia del imperativo reconocimiento de un mínimo de espacio a la entidad territorial. Nos estamos refiriendo al pouvoir municipal ${ }^{17}$, a una categoría de intereses que por su naturaleza no rebasan el ámbito municipal. En consecuencia, este conjunto de competencias no encuentra justificación en una delegación por parte del Estado, «... en cuanto se trata de una comunidad que antes que cualquier regulación estatal cuenta ya con su propia titularidad del poder» ${ }^{18}$.

Dentro de las competencias novedosas, atribuidas a las entidades territoriales, se encuentra la establecida en el artículo 289 a la luz de la cual, por mandato de la ley, los departamentos y municipios ubicados en

17 «Le corps municipaux auront deux éspeces de fonctions à remplir, les unes propres au pouvoir municipal, les autres propres a la administration général de l'état délegués par elle aux municipalités", estatuyó la asamblea constituyente francesa, en el Decreto promulgado el 14 de diciembre de 1789.

t8 Eduardo GARCIA DE ENTERRIA: «Turgot y los orígenes del municipalismo moderno", en Revista de Administración Pública, núm. 33, pp. 79 y ss., diciembre de 1960 , en Fernando ALBI: La crisis del municipalismo, p. 11, Instituto de Estudios de Administración Local, Madrid 1966. 
zonas fronterizas podrán adelantar directamente con la entidad territorial limitrofe del país vecino, de igual nivel, programas de cooperación e integración, dirigidos a fomentar el desarrollo comunitario, la prestación de servicios públicos y la preservación del ambiente.

\section{Administrar sus recursos y establecer los tributos necesarios para el cumplimiento de sus funciones}

Se establece asi constitucionalmente el principio del manejo y disposición directa de los recursos y las rentas de las entidades a través de sus propias autoridades y organismos, sin sometimiento a otros entes, autoridades o al Gobierno nacional. Empero, este propósito, ya en la instancia constitucional, encuentra grandes obstáculos.

\subsection{El manejo presupuestal y la Hacienda pública}

Desarrollan este principio algunas otras normas constitucionales como las establecidas en los artículos 300 numeral $5^{\circ}$ y 313 numeral 5 , que facultan a las autoridades departamentales y municipales, dentro de los primeros diez días de cada legislatura, respectivamente, para dictar o expedir anualmente sus presupuestos de rentas y gastos conforme a sus intereses y criterios, sobre la distribución adecuada de los recursos de la entidad.

Para comprender el verdadero alcance de esta disposición, es menester hacer un análisis sistemático de la Constitución, puesto que tiende a mermar directamente, 0 a través de la legislación, las atribuciones presupuestales de las entidades territoriales.

Asi, la ley orgánica del presupuesto, ha de regular lo correspondiente a la programación, aprobación, modificación, y ejecución de los presupuestos de la nación, de las entidades territoriales y de los entes descentralizados de cualquier nivel administrativo - artículo 352 constitucional.

El artículo 353, estatuye que los principios y las disposiciones del título relativo al régimen económico y de la Hacienda pública, se aplicarán en lo que fuere pertinente, a las entidades territoriales, para la elaboración, aprobación y ejecución de su presupuesto.

Esta norma reduce el campo de acción de las entidades territoriales frente al régimen anteriormente vigente. En efecto, la ley 38 de 1989, orgánica del presupuesto general de la nación, simplemente recomendaba a las 
entidades territoriales acoger, en la redacción de sus estatutos presupuestales, principios análogos a los por ella regulados. El nuevo ordenamiento constitucional, prácticamente deja en manos del legislador, la oriẹntación en el manejo presupuestal de los distintos niveles territoriales.

El problema adquiere connotaciones mayores si analizamos el artículo 344: "Los organismos departamentales de planeación harán la evaluación de la gestión y resultados sobre los planes y programas de desarrollo e inversión de los departamentos y municipios, y participarán en la preparación de los presupuestos de estos últimos en los términos que señale la ley.

»En todo caso, el organismo nacional de planeación, de manera selectiva, podrá ejercer dicha evaluación sobre cualquier entidad territorial»». Resulta indiscutible, que el departamento se coloca en una clarísima posición de supremacía frente al municipio, que a pesar de ser la entidad fundamental de la división político administrativa del Estado - a la luz del nuevo orden-, para efectos prácticos sigue siendo considerado como un «menor» ${ }^{19}$, digno de tutela.»

La estructura de control, fundada sobre una tendencia centralizante, se ve reforzada con el contador general, funcionario de la rama ejecutiva, quien llevará la contabilidad general de la nación y la consolidará con la de las entidades descentralizadas territorialmente o por servicios, cualquiera que sea el nivel a que pertenezcan, excepto la referente a la ejecución del presupuesto cuya competencia se atribuye a la contraloría -artículo 354 constitucional.

Corresponden especificamente al contador general, las funciones de uniformar, centralizar y consolidar la contabilidad pública, elaborar el balance general y determinar las normas contables que deben regir en el pais, conforme a la ley.

Pero también las partidas presupuestales están limitadas en su destinación - por lo demás destinación de alto contenido social, acorde con los más justos postulados del Estado social de derecho-; en efecto, en la distribución territorial del gasto público se han de tener en cuenta las necesidades básicas insatisfechas, la población y la eficiencia fiscal y administrativa, según reglamentación que hará la ley -inc. 2, artículo 350.

Vinculados a la autonomía en el gasto, se reconocen, igualmente, en el artículo 356 respecto de los departamentos, del distrito capital y de los distritos especiales de Cartagena y Santa Marta, los recursos prove-

19 El concepto de control de tutela se justifica con base en el traslado de una figura del derecho privado al de derecho público, según la cual este tipo de control se ejerce sobre los menores incapaces, en este caso, el municipio. 
nientes del situado fiscal, puesto que éstos deben destinarse a financiar servicios tales como educación preescolar, primaria, secundaria, media, salud -en los niveles que establezca la ley-y programas especiales para la niñez.

\subsection{Planeación y presupuesto}

En materia de planeación se han introducido importantes procedimientos de coordinación entre los distintos niveles de la administración pública. A la luz de esta lógica: «Las entidades territoriales elaborarán y aprobarán de manera concertada entre ellas y el Gobierno nacional planes de desarrollo, con el objeto de asegurar el uso eficiente de los recursos y el desempeño adecuado de las funciones que les hayan sido asignadas por la Constitución y la ley...»-artículo 339, inc. 2.

La presencia de las entidades territoriales, está prevista en el consejo nacional de planeación; y no sólo eso, también en las entidades territoriales habrá consejos de planeación. El uno y los otros, constituirán, el sistema nacional de planeación, a tenor del artículo 340 constitucional, aqui reportado.

El plan nacional de desarrollo que ha de elaborar el Gobierno, contará con la participación activa de las autoridades de planeación de las entidades territoriales.

Así las cosas, parece razonable que la ley orgánica del presupuesto se ocupe de la coordinación del presupuesto de las entidades territoriales, con el plan nacional de desarrollo - artículo 352-, pues en realidad, esta perentoria correspondencia ha de estar precedida de una adecuada coordinación y concertación entre el nivel central y los niveles periféricos.

\subsection{Autonomía para establecer los tributos necesarios para el cumplimiento de sus funciones}

Las asambleas a través de ordenanzas, pueden decretar, de conformidad con la ley, los tributos y las contribuciones necesarios para el cumplimiento de las funciones departamentales -artículo 300 numeral 3-. Los concejos municipales también, de conformidad con la ley, votarán los tributos y gastos locales a tenor del numeral 4 del artículo 313.

Las disposiciones citadas, tienen relación en el artículo 338 constitucional, según el cual en tiempo de paz, solamente el Congreso, las asambleas departamentales y los concejos distritales y municipales podrán im- 
poner contribuciones fiscales o parafiscales. Pero lógicamente, únicamente el Congreso es soberano en la materia; los departamentos y municipios están sujetos al marco legal.

Un tal sistema de articulación del régimen tributario parece razonable, máxime si se trata de un Estado unitario; lo que no parece apropiado es la calificación de autónoma que el artículo 287 le atribuye a la potestad impositiva; ésta continúa dentro de los cauces jurisprudenciales, zanjados durante la vigencia de la anterior Constitución. Se trata de una «autonomía” derivada de la ley como se puede deducir del análisis de los artículos 287 numeral $3,388,300$ numeral 4 y 313 numeral 4 .

En materia de impuestos una importante garantía está contenida en el artículo 294: «La ley no podrá conceder exenciones ni tratamiento preferencial en relación con los tributos de propiedad de las entidades territoriales. Tampoco podrá imponer recargo sobre sus impuestos salvo lo dispuesto en el artículo 317\%. - Se trata de la contribución de valorización.

\subsection{Control de la gestión fiscal en las entidades territoriales}

Es de citar el artículo 272 que establece el control de la gestión fiscal de los departamentos, distritos y municipios, que corresponderá a las contralorías ya existentes.

El control de la gestión fiscal de los municipios se le atribuye a las contralorias departamentales, lo que ratifica que el municipio se considera como un incapaz, puesto que queda sometido a la tutela departamental.

Lejos, está aún nuestro ordenamiento jurídico, de instituir órganos de control independientes de la administración territorial respectiva. Sin embargo se debe destacar la atribución, tanto de los tribunales superiores del distrito judicial como de los Tribunales Contenciosoadministrativos, de integrar las ternas, para la designación de contralores.

\subsection{Emisión de títulos y bonos de deuda pública}

Para concluir, conviene recordar otra fuente de financiación de las entidades territoriales: la emisión de títulos y bonos de deuda pública, con sujeción a las condiciones del mercado financiero e igualmente contratar crédito externo, todo de conformidad con la ley que regule la materia -artículo 295 constitucional-. Obsérvese que también en este aspecto, el imperio de la ley es notable. 


\section{Participar en las rentas nacionales}

El buen sentido sugiere que lo que el constituyente quiso decir, es que las entidades territoriales tendrian derecho a participar en las rentas nacionales, ser destinatarias de los emolumentos, no que tendrian autonomía para participar en las mismas.

En desarrollo de este precepto, encontramos el artículo 356 del texto fundamental donde se estatuye - como ya se indicó- que la ley, a iniciativa del Gobierno, determinará el situado fiscal, esto es, el porcentaje de los ingresos corrientes de la nación que será cedido a los departamentos, al distrito capital y a los distritos especiales de Cartagena y Santa Marta, para la atención directa o a través de los municipios de los servicios que les asigne.

Merece destacarse un principio ya arraigado en los ordenamientos europeos: "No se podrán descentralizar responsabilidades sin la previa asignación de recursos fiscales suficientes para atenderlas".

Es también desarrollo del numeral 4 del artículo 287, el 357: «Los municipios participarán en los ingresos correspondientes de la nación. La ley, a iniciativa del Gobierno, determinará el porcentaje mínimo de esa participación y definirá las áreas prioritarias de inversión social que se financiarán con dichos recursos. Para los efectos de esta participación, la ley determinará los resguardos indígenas que se consideren como municipios.

"Los recursos provenientes de esta participación serán distribuidos por la ley de conformidad con los siguientes criterios: 60 por 100 en proporción directa al número de habitantes con necesidades básicas insatisfechas y al nivel relativo de pobreza de la población del respectivo municipio; el resto en función de la población total, la eficiencia fiscal y administrativa y el progreso ilustrado en la calidad de vida, asignando en forma exclusiva un porcentaje de esta parte a los municipios menores de 50.000 habitantes. La ley precisará el alcance, los criterios de distribución aquí previstos y dispondrá que un porcentaje de estos ingresos se invier-. ta en las zonas rurales. Cada cinco años la ley, a iniciativa del Congreso, podrá revisar estos porcentajes de distribución.

"Parágrafo.-La participación de los municipios en los ingresos corrientes de la nación se incrementará, año por año, del 14 por 100 en 1993 hasta alcanzar el 22 como minimo en el 2002. La ley fijará el aumento gradual de estas transferencias y definirá las nuevas responsabilidades que en materia de inversión social asumirán los municipios y las condiciones para su cumplimiento. Sus autoridades deberán demostrar a los organismos de evaluación y control de resultados la eficiente y correcta aplicación de estos recursos y, en caso de mal manejo, se harán acreedores a las sanciones que establezca la ley. 
"Estarán excluidos de la participación anterior, los impuestos nuevos cuando el congreso así lo determine, y por el primer año de vigencia, los ajustes a tributos existentes y los que se arbitren por medidas de emergencia».

Independientemente que los criterios de distribución respondan adecuadamente a las necesidades de la realidad colombiana, el artículo 356 contraría a la ya citada Declaración Universal de la Autonomía Local cuando dispone que: «... los gobiernos locales tendrán derecho a disponer de adecuados recursos financieros propios, distintos de aquellos recursos de otros niveles de gobierno, y tendrán derecho a hacer uso libre de tales ingresos, dentro de los límites que les imponga la ley...». En efecto las áreas de inversión serán definidas por el legislador, a iniciativa del Gobierno.

\section{Otras materias objeto de monopolio del Estado central}

Es posible hacer una extensa lista de las materias, que dentro de un marco institucional autonómico, habrian podido ser atribuidas a las competencias legislativas de las entidades territoriales, sin que por esto se desvirtuara el principio de la unidad nacional.

A manera de ejemplo podemos citar los mecanismos de participación democrática, aspecto que ya anteriormente se indicó, y concretamente las consultas populares y las iniciativas de proyectos presentados por los habitantes de las respectivas comunidades, que deberán ser reguladas tanto en sus requisitos, como en sus formalidades y casos, por el estatuto general de la organización territorial -artículos 105 y 106-. En Italia, país que aún no ha logrado perfeccionar su régimen autonómico, la regulación de estas materias le corresponde al estatuto municipal, a tenor de la ley 142 de 8 de junio de 1990.

Por otro lado, el régimen de responsabilidades, inhabilidades, incompatibilidades, y el período de los miembros de las corporaciones públicas, régimen de los diputados, acceso a la carrera y sistema prestacional de los servidores públicos, también es monopolio del legislador nacional.

Parece entonces razonable concluir, que el marco de acción de las entidades territoriales, está rígidamente predeterminado por el constituyente, $y$ en su defecto por el legislador. Se reproduce entonces, la filosofia orientadora de 1886: centralización política, descentralización administrativa. Pero veamos cuál es el equilibrio de fuerzas entre las entidades territoriales. 


\section{REELABORACIÓN DEL ESQUEMA DESCENTRALISTA: EL DEPARTAMENTO, NUEVO CENTRO DE PODER}

\section{Antecedentes históricos}

Los departamentos fueron en su oportunidad la respuesta histórica de las concepciones unitaristas y centralistas de los constituyentes de 1886, para superar el sistema federal que empezó a perfilarse en nuestro país desde 1853.

En efecto, se readoptó para entonces, de manera integral, la lógica del modelo postrevolucionario francés, que desde la independencia inspiró a nuestros constituyentes.

No olvidemos, que el departamento fue uno de los parámetros adoptados en Francia para superar la heterogeneidad de su mapa político administrativo. Es que el espiritu de provincia aterrorizaba a los teóricos del Estado unitario, entre otros, a Sieyés, porque su historia, su lengua, sus costumbres, podrian propiciar un proceso de fragmentación del Estado.

Se trataba de racionalizar el nivel provincial y de uniformarlo a la luz de criterios cartesianos. En el debate institucional, los intereses particulares se veian como ilegítimos. Existía pues, un conflicto entre el naturalismo y el artificialismo.

Así surgió el departamento, como construcción artificial, aunque en realidad no fue muy distinto a la provincia, concebido en un primer momento, como delimitación de los cuerpos colegiados para la designación de los representantes a la Asamblea Nacional; a esta calidad se le sumaba la de circunscripción administrativa.

Pero sólo a la postre se estructura como colectividad territorial. Tal calidad la adquiere gradualmente, gracias al reconocimiento de una parcial autonomía impositiva, y a la dotación de un presupuesto y de un patrimonio propios. Finalmente, con la ley del 10 de mayo de 1838, se les reconoce personería jurídica ${ }^{20}$.

Con el advenimiento de la República, se acoge también en Colombia la lógica de la estructura departamental, en cuyo vértice se ubica un órgano inspirado, sin duda, en el prefecto napoleónico. En el transcurso

20 Luciano Vandelli: Poteri locali..., op. cit. Sandra Morelli: La Revolución francesa..., op. cit., pp. 152-155. 
de la historia se denota una permanencia del nivel departamental, con algunas variaciones de relieve, sobre todo durante el periodo federal.

También en Colombia se planteó, en el debate político e histórico, la artificialidad de la división departamental: a diferencia de Tulio Enrique Tascón, quien era de opinión que el departamento no tenia ninguna base histórica, Nicolás García Samudio, concluyó en: su hora, que: «Así pues estimamos que una organización departamental que cuente con siglos de existencia no puede desconocerse, ni estimarse como una creación artificial de la ley, porque ello equivaldría a negar la contribución de esenciales factores históricos en la formación institucional del País..." ${ }^{21}$.

En defensa de la institución departamental, irrumpe igualmente José Maria Samper, quien afirma que la razón de ser de los departamentos se fundó en la necesidad de hacer la acción de la Administración más efectiva. Indicaba, este intérprete del régimen derogado que: «... La Constitución ha querido crear un orden jerárquico en todas las operaciones de la Administración pública, formando escalas de negociados, de autoridades y de funciones. Así, después del orden general de la República que todo lo abarca y lo comprende en su grande unidad, hay divisiones y subdivisiones del todo que tienen por objeto facilitar, mediante la clasificación del trabajo gubernativo, la acción de todos los resortes que componen el mecanismo constitucional y legal... la República ha de estar necesariamente dividida en departamentos, por cuanto estas entidades son ruedas necesarias del mecanismo constitucional...".

Como eslabones de la descentralización administrativa, los departamentos alcanzaron, durante la vigencia de la Constitución anterior, algunos grados de «autonomía». El artículo 182, daba peso juridico a esta realidad. Indicaba la norma en cuestión que los departamentos tendrian independencia para la administración de los asuntos seccionales, «... con las limitaciones que establece la Constitución...».

\section{Los departamentos en el actual ordenamiento juridico}

La Constitución política de 1991, transita por estos mismos senderos. Además del reconocimiento general del carácter autónomo ${ }^{22}$, contenido en el artículo 287, y predicable de toda entidad territorial, el artículo 298 señala de manera perentoria que «... los departamentos tienen autonomía para la ad-

21 En "La división departamental y los orígenes del municipio en Colombia», en Boletín de Historia y Antigüedades», vol. XX, núm. 227, p. 14, Organo de la Academia colombiana de Historia, Imprenta nacional, Bogotá 1933.

${ }_{22}$ No olvidemos que cuando el actual texto constitucional hace referencia a la autonomia, quiere decir en realidad autarquía. 
ministración de los asuntos seccionales y la planificación y promoción del desarrollo económico y social dentro de su territorio en los términos establecidos por la Constitución...».

Tal autarquia, que no es autonomía, permite que, sobre la base de un coherente régimen de planeación, se estructuren responsabilidades administrativas, y de desarrollo económico y social para la entidad. El nuevo departamento conforme a estos lineamientos constitucionales, cumple un importante rol como impulsor de la economía regional y el mèjoramiento social.

No obstante, tal perfil está notablemente sujeto a la interferencia del poder central. Por un lado, el gobernador es agente del Presidente de la República para la ejecución de la política económica general; y es precisamente, a la luz de esta disposición, por lo que se debe analizar el numeral 2 del artículo 305, donde se dispone que dentro de las atribuciones del gobernador, se encuentra la de «dirigir y coordinar la acción administrativa del departamento y actuar en su nombre como gestor y promotor del desarrollo integral de su territorio, de conformidad con la Constitución y las leyes".

También las asambleas departamentales cumplen una importante función en la materia, al expedir normas indispensables sobre planeación, desarrollo económico y social; turismo, transporte, medio ambiente, obras públicas, vías de comunicación y desarrollo de sus zonas de frontera; adopción de los planes y programas de desarrollo económico y social y de obras públicas, con la determinación de las inversiones y medidas que consideren necesarias para impulsar su ejecución y asegurar su cumplimiento; coordinación de los planes y programas departamentales con los otros niveles de la Administración -artículo 300-. Obviamente, todas estas atribuciones deben ejercerse dentro del marco legal.

Por lo demás, no se debe olvidar la destinación específica que a tenor del artículo 356 han de tener los recursos del situado fiscal o los recursos corrientes de la nación -artículo 357.

Ahora bien, la posibilidad de logro de todos estos objetivos por parte de las entidades territoriales, debe evaluarse en cada caso específico. Existen diferencias objetivas entre las distintas entidades territoriales, que un espiritu formalista y centralizante ha pretendido ignorar ${ }^{23}$.

Por tanto, parece muy oportuno que el constituyente haya consa-

23 La generalidad y uniformidad del régimen territorial respondió en Francia posrevolucionaria, a la necesidad de dar, entre otras razones, expresión territorial al principio de igualdad, inseparable del carácter universal de la ley, dogma de la filosofía política revolucionaria. 
grado el artículo 302 donde se lee: «La ley podrá establecer para uno o varios departamentos diversas capacidades y competencias de gestión administrativa y fiscal distintas a las señaladas para ellos en la Constitución, en atención a la necesidad de mejorar la administración o la prestación de los servicios públicos de acuerdo con su población, recursos económicos y naturales y circunstancias sociales, culturales y ecológicas» ${ }^{24}$.

Excepción a la generalidad del régimen departamental, se hace también posible a través del numeral 5 del artículo 150 donde se establece que por medio de leyes podrá el Congreso conferir atribuciones especiales a las asambleas departamentales. De tal manera, que según la categorización adoptada, podrá el legislador colaborar con los departamentos menos favorecidos y establecer mecanismos que les permitan obtener el impulso necesario para facilitar una adecuada gestión administrativa y una eficiente prestación de los servicios.

Se trata de crear las condiciones para la formación de múltiples polos de desarrollo en el país, verdadera finalidad de la descentralización.

Es que superando el formalismo juridico, que parte de un a priori conceptual sin correspondencia en la realidad, a saber: la idéntica naturaleza de las entidades territoriales en cuanto a su conformación social, geográfica y económica, se deja atrás esa ruptura, ese desfase entre norma y hecho. Por tanto sólo consultando las diferencias ontológicas entre departamentos, la legislación podrá responder de manera adecuada a las necesidades territoriales y contribuir a implementar un adecuado proceso de planeación.

\section{El gobernador}

La elección popular del gobernador, indudablemente responde al propósito de fortalecer la figura y la entidad territorial que preside.

En efecto, se trata del jefe de la administración seccional y representante legal del departamento. Por lo demás se desempeña como directitucional.

24 Se trata de lo que la doctrina constitucional suele llamar una ruptura cons-

Dice Giuseppe DE VERGOTTINI, en su libro Diritto costituzionale comparato, p. 177, Cedam, Padova 1991: «Un particolare tipo di modifica della costituzione può aversi tramite deroga di sue norme per una determinata fattispecie, mentre per tutte le altre fattispeci possibili tali norme rimangono in vigore" (c.d. "rottura» della costituzione). Para el caso italiano encontramos el artículo 116 de la Constitución, que autoriza, a las regiones especiales, a través de leyes constitucionales, a adoptar peculiares estatutos de autonomía, derogando el Título V, que permanece vigente, para todos los demás casos. 
tor y coordinador de la acción administrativa territorial y de los servicios nacionales en la entidad cuando le hubiere sido delegada esta función por el Presidente de la República. Asimismo, aparece como gestor y promotor del desarrollo integral de su territorio, de conformidad con la Constitución $y$ las leyes.

En desarrollo de tal potestad, presenta a las asambleas departamentales los proyectos de ordenanza sobre planes y programas de desarrollo económico y social, obras públicas, presupuesto anual de rentas y gastos; fomenta, de acuerdo con los planes y programas, las empresas industriales y actividades convenientes al desarrollo cultural, social y económico del departamento que no correspondan a la nación y a los municipios.

Mas no se debe olvidar la naturaleza del gobernador como agente del Presidente de la República, para la ejecución de la política económica general, lo que indudablemente le resta autonomía en el ejercicio de las atribuciones antes enumeradas, como ya se hizo notar en este estudio.

Son de recordar, dentro de las disposiciones constitucionales limitativas de la autonomía financiera, los varias veces citados artículos 356 y 357 , que deben en todo caso orientar la conducta del gobernador.

Y en materia de planeación, ya se dijo aquí, se trata de un régimen que debe estar en perfecta coordinación con las demás instancias administrativas y máxime con la nación, aspecto que, por lo demás, responde a la naturaleza misma de las cosas, en cualquier tipo de Estado que pretenda preservar su fisonomia única. Lo aquí afirmado no obsta para sembrar una voz de alarma, en el sentido de que si la planeación se realiza bajo un paradigma centralizante, va a redundar en sacrificio de su objetivo primario, cual es una adecuada coordinación de los diferentes niveles territoriales, para transformarse en una instancia de imposición vertical de decisiones.

Concreción de tal imperativo es el inciso segundo del artículo 339 , ya citado, pero que no está de más volver a reportar: "Las entidades territoriales elaborarán y adoptarán de manera concertada entre ellas y el gobierno nacional planes de desarrollo, con el objeto de asegurar el uso eficiente de sus recursos y el desempeño adecuado de las funciones que le hayan sido asignadas por la constitución y la ley".

Como la naturaleza y cuantía de los recursos del departamento son, en gran medida, objeto de regulación legislativa, no resta más que concluir, que el espacio de acción del gobernador está notablemente reducido. Sigue prevaleciendo su carácter de servidor administrativo; para identificar este prevalente perfil, basta revisar el artículo 305 , donde se enumera una serie de atribuciones de gestión tales como dirigir y coordinar la acción administrativa del departamento; nombrar y remover libremente a los 
gerentes y directores de establecimientos públicos y de las empresas industriales y comerciales del departamento...; crear, suprimir y fusionar los empleos de sus dependencias, señalar sus funciones...; suprimir o fusionar las entidades departamentales...; velar por la exacta recaudación de las rentas departamentales; escoger de ternas enviadas por el jefe nacional respectivo, los gerentes o jefes seccionales de los establecimientos públicos del orden nacional, que operen en el departamento, de acuerdo con la ley; ejercer las funciones administrativas que le delegue el Presidente de la República; etc.

Podemos en todo caso, reconocer algunas atribuciones politicas tales como objetar, por motivos de inconveniencia, los proyectos de ordenanza o convocar a las asambleas departamentales a sesiones extraordinarias.

Si a esto se le suma el carácter de agente del Presidente de la República para el mantenimiento del orden público, para la ejecución de la pólítica económica general, así como para aquellos asuntos que mediante convenio la nación acuerde con el departamento, resulta que el reforzamiento de la figura del gobernador, como suprema autoridad departamental, es relativo. Máxime cuando éste puede ser destituido por el mismo Presidente de la República, a pesar de haber sido elegido popularmente.

Y'como ya se dijo, la única real e importante consecuencia política de la elección popular de gobernadores, la encontramos en el artículo 259: "Quienes eligen gobernadores y alcaldes, imponen por mandato al elegido el programa que presentó al inscribirse como candidato. La ley reglamentará el ejercicio del voto programático».

Permanece, pues, una concepción centralizante, donde la política es monopolio del Estado central y sólo la instancia administrativa es susceptible de descentralización. La estructura piramidal-jerarquizada sigue siendo pilar de nuestro ordenamiento territorial.

Esta aseveración se ve consolidada además ante el fortalecimiento del departamento frente al municipio.

\section{Relaciones del departamento y del municipio}

El artículo 298 constitucional, estatuye expresamente que los departamentos «... ejercen funciones administrativas de coordinación, de complementariedad de la acción municipal, de intermediación entre la nación y el municipio...", lo que responde ampliamente a la naturaleza de la ins- 
tancia departamental, siempre y cuando prevalezca este carácter, sobre el de entidad con funciones de administración directa ${ }^{25}$.

Dentro de similar lógica, se redactó el inciso segundo del artículo 288: «las competencias atribuidas a los distintos niveles territoriales serán ejercidas conforme a los principios de coordinación, concurrencia y subsidiariedad en los términos que establezca la ley».

La misma clave de interpretación de las relaciones departamentomunicipio, está reproducida en el artículo 300 numeral 10, cuando indica que dentro de los términos que señale la ley, servicios tales como la educación, la salud, el deporte, podrán ser regulados para su prestación, en concurrencia y colaboración entre departamentos y municipios.

En efecto el departamento debe procurar, además, colmar los vacíos de la acción municipal frente a los asociados. El mecanismo de la complementariedad se relaciona con el de la subsidiariedad, lo que se debe entender como el proyectarse del departamento funcionalmente, no en forma tal que absorba o sustituya al municipio, sino en el sentido de colaborar con dicha entidad. Tal diferenciación, en la realidad institucional, puede resultar muy sutil —véase cita 26.

En desarrollo de este principio, los artículos 298 y 344, permiten establecer un marco general de planeación, que en muchos aspectos vincula inevitablemente las entidades territoriales. Por otro lado, el artículo 300 , relativo a las atribuciones de las asambleas, dispone: «Expedir las disposiciones relacionadas con la planeación, el desarrollo económico y social, el apoyo financiero y crediticio a los municipios, el turismo, el transporte, el ambiente, las obras públicas, las vias de comunicación y el desarrollo de sus zonas de frontera».

Se prevé además un control a posteriori, ejercido por los organismos departamentales de planeación sobre los planes y programas de desarrollo e inversión de los municipios. Tal fiscalización adquiere razón de ser, según los preceptos de la ciencia de la administración, cuando todas las instancias previas de coordinación han resultado insuficientes. ${ }^{26}$

25 El profesor VANDELLI refiriéndose a este nivel territorial, muestra la clara tendencia, en la actual Europa de las regiones, a concebirlo como un nivel intermedio de programación. Dice el autor que las provincias promueven, entre otras, las actividades programáticas de los comunes. No se puede desconocer, en todo caso, que de reciente se denota un fortalecimiento de esta entidad a partir de la asignación de funciones de administración activa o directa. La fuente de la nueva esfera de competencias ha sido la legislación regional. Poteri locali..., op. cit., p. 413.

${ }_{26}$ Vittorio MORTARA: Introduzione alla pubblica administrazione italiana, p. 72, Franco Angeli editore, Milano 1990. Afirma el autor que obviamente una organización entre más compleja sea, plantea mayores problemas de coordinación. La coordinación puede ser el producto de una confrontación entre varias personas, o ser el resultado de 
Por lo demás, los departamentos participan en la preparación de los planes municipales - artículo 344-, lo que constituye una medida regresiva y autoritaria que debilita en todos sus aspectos la autonomía local. La elaboración de un presupuesto, como lo reconoce la doctrina y la práctica administrativas, no es un mero problema de técnica. Es el resultado de profundos análisis de carácter político y social, en cuanto al recaudo de unos recursos y su proyección como respuesta a las prioridades advertidas en los respectivos planes municipales de desarrollo. De aceptarse la intervención de otras instancias, bien puede suceder que el presupuesto responda a intereses ajenos a los de la respectiva entidad local. Se debilita por consiguiente, el principio de autonomía contable ${ }^{27}$.

En materia económica es de resaltar la potestad departamental contenida en el artículo 300 numeral 2 del texto constitucional, para expedir disposiciones relacionadas con el apoyo crediticio y financiero de los municipios - concordancia con el artículo 356.

Así las cosas, parece posible concluir, que la tutela, tan arduamente criticada en 1986, de los departamentos sobre los municipios, se revive innecesariamente a través de este precepto constitucional. Es que si verdaderamente se considera al municipio como entidad fundamental de la división político administrativa del Estado, el departamento ha de tener, respecto de éste, tan sólo una función de colaboración, mas no de imposición o intromisión.

Supremacia del departamento sobre el municipio se denota también, en la potestad del gobernador de revisar los actos de los concejos municipales y de los alcaldes y, por motivos de inconstitucionalidad o ilegalidad, remitirlos al tribunal competente para que decida sobre su validez. Tal intervención, en todo caso, no impide que los actos correspondientes nazcan a la vida jurídica. Se sigue aquí con la tendencia, prevalente en los países de derivación francesa, de «jurisdiccionalizar» el control.

En el numeral 6 del artículo 300 , es reconocible otro instrumento de fortalecimiento de la instancia departamental, al permitirle, con sujeción a la ley, crear y suprimir municipios, segregar y agregar territorios munici-

\footnotetext{
la imposición de la voluntad de una sola persona; en el primer caso se podrá hablar de coordinación espontánea, en el segundo caso de control. En la práctica y distinguiendo entre el plano formal y el informal, se pueden verificar situaciones aparentemente contradictorias. Es decir, que bien puede suceder, que una situación prevista por la ley como de coordinación, en la realidad se transforme en control, porque uno de los sujetos implicados tiene un poder informal superior al de los otros.

${ }_{27}$ Por autonomia contable se entiende autonomía organizativa; capacidad de actuar autónomamente a través de instrumentos de ordenación de las finanzas públicas. Se concreta en la configuración y predisposición del presupuesto, en la gestión de los procedimientos financieros para imputación de los gastos, en la administración de los bienes, etc. En Franco MAStRAgostino et alii: Le autonomie territoriali, p. 373, II Mulino, Bologna 1984.
} 
pales y organizar provincias, sin que se prevea ningún tipo de intervención de las autoridades municipales o un referéndum para que la población interesada se pronuncie al respecto.

Bajo la misma perspectiva, las provincias serán creadas por ordenanza a iniciativa del gobernador. Sin embargo para este supuesto de hecho, sí está prevista la intervención de los alcaldes municipales y de los ciudadanos -artículo 321 constitucional.

Es de resaltar la disposición contenida en el artículo 301, cuando señala que previo mandato del legislador, las asambleas departamentales pueden delegar en los concejos municipales las funciones que ella misma determine. En ejercicio de esta regulación y dentro de un amplio concepto de colaboración, eventualmente los municipios pueden ver incrementado su campo de acción en asuntos que estén en capacidad de asumir. Además, sabiamente el constituyente precluyó descentralizar responsabilidades, sin la previa asignación de recursos fiscales suficientes para atenderlas -articulo 356.

Específicas condiciones por las que atraviesa el país, explican cómo, también la técnica de manejo del orden público, se constituye en uno de los instrumentos centralizantes del Estado colombiano.

Los artículos 296 y 315 numeral 2 constitucionales, someten a estricto orden jerárquico el mantenimiento del orden público en todo el territorio nacional. Tratándose de los municipios, los actos y las órdenes del Presidente de la República y del gobernador, se aplicarán de manera inmediata y preferente respecto a los de los alcaldes, a tenor del 296 . El artículo 315 de la Constitución complementa esta disposición al estatuir la obligación para los alcaldes de conservar el orden público en el municipio, de conformidad con la ley y las instrucciones y órdenes que reciba del Presidente de la República y del respectivo gobernador.

Se debe recordar, además, que tanto las gobernaciones como las alcaldías, hacen parte de la estructura de la rama ejecutiva y que el gobernador es, también en materia de orden público, agente del Presidente.

Se trata de otra de las manifestaciones de la centralización política, que en el anterior régimen constitucional estaba prevista en el artículo 120 numeral 7, que encomendaba al Presidente de la República como jefe del Estado y suprema autoridad administrativa la función primordial de conservar en todo el territorio el orden público y restablecerlo donde fuere turbado. Aunque la disposición se reproduce en el artículo 189 del texto actual, el constituyente procedió a desarrollar en términos puntuales tal potestad. 
La ley 4 de 16 de enero de 1991, sobre orden público interno, regula el cumplimiento de la disposición constitucional en comento. Aunque fue expedida durante la vigencia del anterior ordenamiento, obedece en esencia al mismo fenómeno. En efecto, los artículos $7 .^{\circ}, 8 .^{\circ}$ y $9 .^{\circ}$ recogen las previsiones que se elevaron a preceptos constitucionales en los artículos 296, 303 y 315 numeral 2; pero además dispone un estricto régimen disciplinario para los funcionarios infractores, que puede llegar hasta la suspensión o destitución en el ejercicio del cargo.

De todo lo anterior nos es posible concluir, que el nuevo régimen constitucional se perfila en su sustancia filosófica, sin alterar los postulados del 86 de centralización política y descentralización administrativa. La innovación consiste en racionalizar la administración de manera más técnica, para implementar adecuadamente la pirámide jurídica, donde el Estado central prevalece sobre las demás entidades territoriales, y a su vez, el departamento acapara, los pocos vestigios de poder restantes. Por tanto la base de la pirámide, que retóricamente se define como entidad fundamental de la división político administrativa del Estado, goza de mínimo espacio de acción autónoma.

\section{EL PAPEL DEL MUNICIPIO COLOMBIANO}

\section{Antecedentes históricos}

El núcleo de inmediatez entre el Estado y los asociados lo constituye el municipio. En este sentido los sistemas institucionales de organización municipal, son el producto del reconocimiento jurídico de un contexto sociológico, cultural y económico homogéneo.

El municipalismo propugna soluciones a las problemáticas del hombre en la vida comunitaria, propone condiciones mínimas de civilización moderna para los asociados. Como afirma Ives Oliceira: «... la doctrina municipalista, impregna en su filosofía un contenido eminentemente valorizador del hombre... Procura corregir las desigualdades humanas... mediante la adecuación de un mínimo de condiciones de civilización moderna... a través de soluciones colectivas... La igualdad de todos frente a la ley es sólo posible, en la medida en que cada individuo en su núcleo social [el municipio] pueda disfrutar de los instrumentos ofrecidos por la civilización moderna» ${ }^{28}$.

${ }^{28}$ Que è Municipalismo; associaçao Brasileira de Municipios, Cuadernos de Cultura Municipalista, núm. 1, p. 22, Río de Janeiro 1959; en Jaime Orlando SANTOFIMIO: Régimen de la administración municipal, en imprenta. 
Realmente el municipio es una institución de larga tradición histórica, no sólo en Colombia, sino en el mundo. ${ }^{29}$

Al momento de la conquista ibérica de América indígena - hoy se habla de encuentro-, operó un traslado de la filosofía municipalista a estos territorios. Pero el poder municipal, símbolo de autonomía, de lucha y de relativa libertad ciudadana, en el Nuevo Continente adquirió connotaciones sustancialmente distintas ${ }^{30}$.

La institución, con todo, logró un arraigo notable, lo que facilitó a la élite dominante en Colombia, a partir de la Independencia, instaurar un

29 En efecto, parte de la doctrina suele afirmar que no se trata de un fenómeno propio del Estado moderno, sino que sus antecedentes se remontan a los primeros núcleos sociales de la humanidad.

No se comparte sin embargo la equiparación que frecuentemente se suele hacer entre clan y municipio; en el primero prevalece el elemento consanguíneo y en el segundo el territorial. Si se adopta, por lo demás, la tesis legal positivista, sobre la naturaleza del municipio, resulta que éste es una creación legal, a diferencia del clan, que precede en su existencia a toda organización jurídica. Tal aseveración es desvirtuable a la luz de la teoría iusnaturalista; para esta escuela el municipio es una institución social y política preestatal. Por tanto existe desde los albores de la civilización y subsistirá siempre -cfr. Alcides GreCA-: Revista de derecho y administración municipal, 1944; en Ives DE OLIVEIRA: "Curso...", op. cit., p. 13.

Otros autores consideran que los clanes son formas originales de organización estatal y no municipal. El municipio, afirman, corresponde estudiarlo en un contexto de subordinación al poder soberano - cfr. Rafael URIBE URIBE: «El municipio y la emancipación", en Revista jurídica, núm. 33, Bogotá, julio de 1966-. Parece en todo caso que no puede desconocerse el gran aporte romano a la vida municipal, al diferenciar esta entidad del concepto de Estado. De este parecer es el profesor Diogo LORDELLO DE MELLO, en Jaime Orlando SANTOFIMIO, Régimen administrativo..., op. cit.

${ }_{30}$ Señala el profesor Augusto HeRnANDEZ BECERRA, como causas determinantes de una caracterización propia del municipio colombiano las siguientes: 1) la enormidad de las distancias y el consiguiente aislamiento de las localidades coloniales; 2) la frecuente ignorancia juridica de los conquistadores y fundadores; 3 ) la naturaleza privada y militar de la aventura conquistadora; 4) lo exótico del medio y de las culturas sometidas, etc., en "Apuntes para la historia del municipio en Colombia", sobretiro de Memoria del II Congreso de historia del derecho mexicano, p. 225, México, D.F., 1980.

Sin embargo más que de lo exótico de las culturas sometidas, parece menos polarizado hablar de la absurda pretensión de imponer un ordenamiento jurídico - gestado en otras condiciones culturales -, a una civilización totalmente extraña. Con tal empresa lo que se emprendió fue un proceso de aculturación cuyas nefastas consecuencias no se han superado. Pero específicamente en materia de organización territorial pareceń oportunas las siguientes consideraciones: «Respecto del clan los españoles introdujeron dos reformas sustanciales; por una parte modificaron la estructura de parentesco: los hijos de india casada fueron considerados hijos del marido, de acuerdo con la presunción romana de paternidad; contrariamente, los hijos de india soltera continuaron siendo de la familia de la madre. En consecuencia, a través del derecho indiano, según la real cédula del 10 de octubre de 1618, la estructura de parentesco se transformó en patriarcal». Sandra Morelli: La Revolución..., op. cit., p. 16.

Por lo demás, el clan recibió por parte de los españoles un descalabro solemne con cruz y espada. "El derecho indiano royó implacablemente, aunque con lentitud, todos sus costados, hasta diluir los hombres sobre la tierra y hacerlos participar en la vida civil a través del municipio de su vecindad. No fue un proceso fulminante sino evolutivo y lento". Guillermo HERNANDEZ: De los chibchas a la colonia y a la República, p. 89, Instituto Colombiano de Cultura, Bogotá 1949. 
régimen municipal, general y uniforme. En efecto, todo el territorio fue dividido en municipios; sus autoridades eran: el alcalde, jefe de la administración municipal y agente del ejecutivo - su superior jerárquico-; al lado se previó un órgano colegiado de naturaleza administrativa. El cuadro se completa con la institución del poder de tutela ${ }^{31}$.

Este esquema jurídico se fue perfilando desde la Independencia hasta las últimas décadas del presente siglo, lo que resultó altamente funcional para un Estado centralizado, en detrimento, lógicamente, de toda posibilidad de autonomía local.

Pero de la importancia del nivel municipal ha tomado conciencia el legislador colombiano desde los años ochenta. En efecto, se ha pretendido dotar a los municipios de claras atribuciones administrativas y fiscales y propiciar condiciones adecuadas para prestar los servicios encomendados por la ley. Se ha tratado, además, de promover el desarrollo de su territorio, el mejoramiento sociocultural de sus habitantes, y, en fin, garantizar la participación ciudadana y comunitaria en el manejo de asuntos públicos de carácter local. Es de destacar, bajo esta perspectiva, el acto legislativo número 1 de 1986, que introdujo la elección popular de alcaldes y la consulta popular municipal.

El fortalecimiento de los fiscos municipales, a través de la ley 14 de 1983 y de las leyes 11 y 12 del 86, es también digno de mención, así como, las condiciones para la creación de municipios, el régimen de las inspecciones de policia, la asociación de municipios, las juntas administradoras locales, las comunas y corregimientos, la participación comunitaria en los servicios públicos, etc.

\section{El municipio en el nuevo ordenamiento territorial}

Dentro de la tendencia a fortalecer el municipio se mantuvo la Asamblea Nacional constituyente, al consagrar en el artículo 311: «Al municipio como entidad fundamental de la división político administrativa del Estado le corresponde prestar los servicios públicos que determine la ley, construir las obras que demande el progreso local, ordenar el desarrollo de su territorio, promover la participación comunitaria, el mejoramiento social y cultural de sus habitantes y cumplir las demás funciones que le asignen la constitución y las leyes".

Se trata pues, de una entidad territorial $-286-$, con personeria ju-

31 Se trata de un término propio del derecho privado para significar que el municipio, como el menor, era considerado incapaz. 
rídica -artículo $4 .^{\circ}$ D. 1333 de 1986 -, titular de derechos y obligaciones. En tal calidad, el territorio es un elemento constitutivo del municipio, y no tan sólo una circunscripción que determina el ámbito de su competencia. Consecuencia de su naturaleza es, el poseer un gobierno propio que ejerce su jurisdicción y competencia sobre la población alli residente, domiciliada o transeúnte, según el caso.

Pero volviendo al actual sistema constitucional es de anotar que el verdadero contenido del artículo 311 está sujeto al ámbito de acción que le reconozca el legislador nacional; el nuevo esquema municipal es hijo del legislador, como se deriva de la lectura de la gran mayoría de sus atribuciones constitucionales.

En realidad, si bien el consejo reglamenta los servicios, aprueba los planes de desarrollo, el presupuesto municipal y promulga disposiciones sobre medio ambiente, es el alcalde quien tiene la iniciativa, por mandato constitucional, en estos asuntos. $Y$ no olvidemos, que éste debe velar porque los preceptos de la corporación municipal se cumplan en forma coordinada con las autoridades departamentales, en materia de desarrollo económico y social.

Asi las cosas, se observa que el nuevo ordenamiento establece situaciones de prevalencia del departamento sobre el municipio; aspecto que en nuestra opinión, significa un evidente retroceso en cuanto al ámbito ganado durante la vigencia de la anterior Constitución.

Sorprende además, aquella disposición constitucional, ya mencionada, a la luz de la cual el Presidente y los gobernadores, en los casos taxativamente señalados por la ley, suspenderán o destituirán a los alcaldes -inciso 2, artículo 314-, lo que refuerza la lógica de una administración piramidal y de paso tiende a desconocer la envergadura de la legitimidad otorgada por la población municipal a su alcalde y que encuentra su instancia de control en el voto programático.

La relación de jerarquía se refuerza en el numeral 2 del artículo 315 relativo al orden público, que oportunamente se analizó.

Las conclusiones aqui esbozadas se complementan, con lo que se dijo en el aparte de este escrito, sobre la relación departamento-municipio.

\section{Comunas y corregimientos}

Resta anotar, que con miras a lograr una administración eficiente y eficaz, los concejos podrán dividir sus municipios en comunas cuando se 
tràte de áreas urbanas, y, en corregimientos, en el caso de zonas rurales. Se trata también, de fortalecer la participación ciudadana, materias en las que ya se habian adelantado importantes pasos durante el proceso de descentralización emprendido en la pasada década.

Dichas divisiones estarán presididas por una junta administradora local, con funciones de planificación, de vigilancia en la prestación de servicios, con potestades propositivas y de distribución de las partidas globales asignadas por el presupuesto municipal. En fin, el concejo puede delegar a las juntas funciones específicas, lo que contribuye a la eficiencia administrativa municipal.

\section{Categorización de municipios y asociaciones}

La generalidad y uniformidad del régimen municipal, que como ya se ha indicado aqui, responde a los intereses de un Estado unitario que pretende privilegiar el principio de la igualdad jurídico-formal en detrimento de las específicas condiciones ontológicas de cada municipio, se vio hace ya algunos años superada con el establecimiento de la categorización de municipios. Sin embargo, esta norma, lamentablemente, sólo fue objeto de desarrollo para efectos de establecer los sueldos de los alcaldes, pero sus aspiraciones en realidad iban más allá; lo que se pretendía era, entre otras, racionalizar la planificación.

El nuevo texto constitucional recoge nuevamente esta figura, en los siguientes términos: «La ley podrá establecer categorías de municipios de acuerdo con su población, recursos fiscales, importancia económica y situación geográfica, y señalar distinto régimen para su organización, gobierno y administración» -artículo 320 .

Desaparece, por el contrario, del rango constitucional, la asociación de municipios, lo que no significa de ninguna manera su preclusión. A nuestro entender, en todo momento pueden los municipios, como sujetos de derecho que son, asociarse entre sí, con miras a la prestación común de un servicio o a la realización de una obra. El régimen de contratación por lo demás, puede ser el propio del derecho privado en la medida en que se trata de sujetos iguales entre sí. 


\section{LOS DISTRITOS}

Dentro de la concepción tradicional, nuestro ordenamiento constitucional asimilaba los municipios a los distritos municipales y se trataba de términos que identificaban un mismo fenómeno, aunque existieran distritos especiales. La Constitución de 1991 por el contrario, se refiere a fenómenos distintos. Se trata de entidades territoriales con propia identidad, que constituyen una excepción al régimen municipal general y uniforme, en consideración de criterios extrajurídicos ${ }^{32}$.

A diferencia de los departamentos y municipios, se pueden diferenciar por su origen, dos tipos de distritos: los creados a nivel constitucional, como Santa Fe de Bogotá, Distrito capital; Cartagena de Indias, distrito turístico y cultural y Santa Marta, distrito turístico, cultural e histórico -artículos 322-328- y, por otro lado, los que de conformidad con el artículo 150 numeral 4, el legislador puede proceder a crear.

El Distrito capital es una entidad territorial que constituye, como su nombre lo indica, la sede de los poderes nacionales de la República; además de ser capital de Cundinamarca, es circunscripción electoral independiente de este departamento para la elección de representantes a la cámara, gobernador y diputados a la Asamblea.

Durante largos años, el distrito especial había vivido en una situación calificada como de limbo jurídico, por cuanto no existía claridad sobre el régimen legal al cual debía estar sometido y prevalecian tendencias que lo equiparaban a los demás municipios. Al respecto dice el profesor VIDAL PERDOMO: «... una ley reciente adoptada por el Congreso de la República tuvo que venir a decir lo que parecía elemental en derecho: las leyes municipales se aplican al distrito especial de Bogotá mientras no sean opuestas a su estatuto especial (Decreto-ley 3133 del 68). La etapa que dicha ley (8. ${ }^{a}$ de 1991) cerró se denominó 'limbo jurídico' para Bogotás " 33 .

Así, el nuevo texto constitucional, de manera expresa determinó que el régimen político, fiscal y administrativo del distrito capital será el que determine la Constitución, las leyes especiales que para el mismo se dicten y las disposiciones vigentes para los municipios.

32 Salvo para el caso de Santa Fe de Bogotá, - que presenta aspectos peculiares, puesto que es además de sede del Gobierno nacional y departamental, la ciudad más poblada de Colombia, y constituye polo de desarrollo económico-, parece viable afirmar que la institución de distritos habria podido obviarse con una adecuada categorización de municipios, lo que es sin lugar a dudas mucho más técnico.

${ }_{33}$ Jaime VIDAL PERDOMO: «Bogotá: ¿distrito especial? ¿Distrito.capital o area metropolitana?", en Estatuto juridico de las capitales y áreas metropolitanas, VV.AA., p. 171, Universidad Externado de Colombia, Bogotá 1991. 
De las condiciones sociológicas de Bogotá distrito capital se comentó en su momento: «Lo metropolitano, traducido en el contexto territorial de varias entidades municipales, no puede derivar en entidad territorial. De aceptarse esta tendencia, desaparecerían las unidades básicas de nuestra organización política, perdiéndose el esfuerzo local frente a necesidades típicamente locales, generándose, por otra parte, 'monstruos citadinos', de clara estirpe centralista, como el engendrado con el Distrito Especial de Bogotás ${ }^{34}$.

En respuesta a la tendencia centralizante que inspiraba el esquema jurídico de la Capital nacional, el nuevo texto constitucional estatuyó: "Con base en las normas generales que establezca la ley, el concejo, a iniciativa del alcalde dividirá el territorio distrital en localidades, de acuerdo con las características sociales de sus habitantes, y hará el correspondiente reparto de competencias y funciones administrativas» -inciso 3 , artículo 322.

La organización del distrito capital debe conciliar el interés general, en este caso distrital, con el interés de cada una de las unidades que lo conforman, llámense zonas, localidades o antiguos municipios. Se trata de lograr eficiencia y eficacia en la prestación de los servicios públicos, a través de una adecuada coordinación y planificación; asimismo, se quiere propiciar la participación y expresión de los intereses parciales reconocibles en el ámbito distrital. Por esta razón parece afortunada la fórmula constitucional que dice: «A las autoridades distritales corresponderá garantizar el desarrollo armónico e integrado de la ciudad y la eficiente prestación de los servicios a cargo del distrito; a las locales, la gestión de los asuntos propios de su territorio» -inciso 4, artículo 322.

Por tanto, con base en las normas o criterios que establezca la ley, el concejo, a iniciativa del alcalde, dividirá el territorio distrital en localidades, de acuerdo con las características sociales de sus habitantes.

Parece ser que tales localidades han de tener la naturaleza de circunscripciones administrativas para la prestación de servicios propios o delegados por el concejo; funciones propositivas, de control de la calidad de los servicios públicos, etc. De modo que, además de tener a su cargo la prestación de algunos servicios, constituirán instancia de participación ciudadana - como ya antes se anotó-. Esta solución permitirá acortar las distancias entre el ciudadano y la administración.

Las localidades estarán presididas por un alcalde local que será designado por el alcalde mayor, de ternas enviadas por la correspondiente junta administradora local. La ley deberá establecer si el alcalde mayor podrá proceder a suspenderlos o destituirlos y la duración de su período.

${ }^{34}$ Jaime Orlando SANTOFIMIO: "Aspectos jurídicos de la planeación y los servicios en las áreas metropolitanas colombianas», en Estatutos jurídicos de las capitales..., op. cit., p. 168. 
Existirá en cada localidad una junta administradora local de elección popular, cuya importancia es de destacar, en cuanto distribuirá y apropiará las partidas globales que en el presupuesto anual del distrito se asignen a las localidades -articulos 323 y 324.

Lo que la reciente doctrina italiana suele llamar la «estatalización» o predominio del Estado central en la organización de las ciudades capitales o áreas metropolitanas, está contenida en el inciso 4 del artículo 323, cuando se establece que el Presidente de la República suspenderá o destituirá al alcalde mayor, en los casos taxativamente indicados en la ley.

Una adecuada canalización de la participación ciudadana a través de las localidades, exige la implementación de un sistema de residencia, de tal manera que el elegido tenga un vínculo con la localidad respectiva, bien sea porque allí reside, bien sea porque allí desarrolla una actividad comercial, industrial, laboral o profesional.

En fin, los artículos 325 y 326 prevén, respectivamente, por un lado, la posibilidad que el distrito capital conforme un área metropolitana con municipios circunvecinos, o una región con uno o más departamentos $y$, por el otro, la incorporación de los municipios circunvecinos al distrito capital, previa aprobación de la ciudadanía municipal implicada. En tal caso al municipio anexo, se le aplicará el régimen jurídico de la localidad.

No parece afortunada esta norma que puede agigantar la conurbación ya monstruosa del distrito capital; es que las medidas económicas, sociales, urbanísticas y de planificación, deberian orientarse a limitar su crecimiento, a todas luces, desproporcionado.

Pero además, no parece razonable, a menos que existan estímulos fiscales o un beneficio directo - por ejemplo, en materia de prestación de servicios-, que los municipios, nominalmente autónomos, pero en todo caso autárticos, pierdan su estatus de entidad territorial para convertirse en localidades, esto es, en circunscripciones administrativas. Será menester esperar el paso del tiempo para conocer la real eficacia del artículo 326 en comento.

\section{LAS AREAS METROPOLITANAS}

El área metropolitana aparece como una extensión geográfica densamente urbanizada, donde se estructura un polo de actividad económica, cuyo particular desarrollo se manifiesta en el sector secundario y terciario; por tanto, se trata de dos fenómenos que se implican mutuamente: urbanización 
e industrialización. Asimismo se caracteriza por una alta densidad demográfica; la conjunción de todos estos aspectos tiene incidencia directa en la demanda de servicios: transporte, agua, alcantarillado.

"En el fenómeno metropolitano las demandas son cuantitativa y cualitativamente distintas a las estrictamente locales, es decir, a aquellas que conciernen a cada una de las unidades que integran el área; no se trata tan sólo de la suma de realidades urbanas - de ciudades- que se extiende por un espacio geográfico. Es que, además, hay varias jurisdicciones político-territoriales, contiguas y superpuestas entre sí, una forma de producción propia y una cultura específica.» ${ }^{35}$

Las bases constitucionales para la implantación en Colombia de las áreas metropolitanas, ya estaban contenidas en el artículo 198 del texto derogado. En desarrollo de tal disposición, el artículo $1 .^{\circ}$ del decreto 3104 de 1974 indicaba que correspondía al área metropolitana la promoción, planificación y coordinación del desarrollo conjunto y la prestación de servicios de dos o más municipios. Se considera que se captó a fondo la idea de la realidad metropolitana, cuando el artículo de la norma citada exige como requisito para la creación del área, que el departamento nacional de planeación conceptúe sobre la existencia de una unidad territorial con estrechas vinculaciones de orden físico, demográfico, económico, social y cultural que exijan su desarrollo integrado y permitan la mejor prestación de los servicios públicos. ${ }^{36}$

Bajo la misma perspectiva, el artículo constitucional 319 recita: "Cuando dos o más municipios tengan relaciones económicas, sociales y físicas, que den al conjunto características de un área metropolitana, podrán organizarse como entidad administrativa, encargada de programar y coordinar el desarrollo armónico e integrado del territorio colocado bajo su autoridad; racionalizar la prestación de los servicios públicos a cargo de quienes la integran y, si es el caso, prestar en común algunos de ellos, y ejecutar obras de interés metropolitano...».

Sin embargo, cuando el mismo artículo atribuye al legislador nacional, la estructuración de un régimen administrativo y fiscal especial, así como aspectos relativos a la participación y las consultas populares, se olvida que cada área, presenta especificidades propias, que sólo con una adecuada autonomía podrian afrontar. Es de esperarse que la ley no sea excesivamente reglamentaria.

Surge otra duda de la lectura del texto aquí citado: el área metropolitana se conforma a partir de los resultados positivos de una consulta

35 Sandra MORELLI: «Algunas consideraciones en materia de áreas metropolitanas", en Estatutos juridicos..., op. cit., p. 123.

${ }_{36}$ Jaime Orlando SANTOFIMIO: Estatutos..., op. cit., p. 158. 
popular de los municipios interesados. Pero resulta que lo metropolitano, como ya dijo antes, es un fenómeno sociológico antes que jurídico. Y debido a la relevancia de las funciones y de los objetivos que debe cumplir, resulta que la voluntariedad puede dar al traste con tan importante fórmula organizativa. No olvidemos que lo metropolitano es un fenómeno que trasciende los límites de la región misma implicada en la conurbación. Tratándose de un polo de desarrollo económico, su interés es también nacional y por tanto se considera que la inclusión de municipios a lo metropolitano deberia ser obligatoria.

\section{LAS PROVINCIAS}

\section{Breves antecedentes históricos}

Históricamente Colombia presenta antecedentes importantes en materia de provincias. Ya desde 1821 la Gran Colombia fue dividida en provincias, presididas por un gobernador agente del intendente. Las provincias permanecen, al lado del nivel departamental en 1830; y su existencia se reitera en el 32, cuando se eliminan los departamentos. La misma estructura alimenta el texto del 43.

Pero la edad de oro de las provincias se inaugura en 1853, cuando a éstas se les otorga la titularidad del pouvoir municipal, en estos términos: "Cada provincia tiene el poder constitucional bastante para disponer lo que juzgue conveniente en su organización, régimen y administración interior" - artículo 48-. Sin embargo, la provincia sigue siendo circunscripción para la administración de los negocios generales del Estado ${ }^{37}$.

El régimen federal pareció, por el contrario caracterizarse por su antiprovincialismo ${ }^{38}$.

En el 86, la provincia permanece pero tan sólo como circunscripción administrativa, hasta que se eliminan en 1936.

37 De la grandeza del régimen provincial da cuenta el profesor Carlos RESTREPO Piedrahita en su obra: Constituciones de la primera república liberal, tomos I-II, Universidad Externado de Colombia, Bogotá 1979.

${ }_{38}$ Ibidem, tomos III, IV y V. 


\section{La provincia en la Constitución de 1991}

Esta entidad, reaparece en el texto del 91 en los siguientes términos: «Las provincias se constituyen con municipios o territorios indígenas circunvecinos, pertenecientes a un mismo departamento.

"La ley dictará el estatuto básico y fijará el régimen administrativo de las provincias que podrán organizarse para el cumplimiento de las funciones que les deleguen entidades nacionales o departamentales y que les asignen la ley y los municipios que la integran.

"Las provincias serán creadas por ordenanza, a iniciativa del gobernador, de los alcaldes de los respectivos municipios o del número de ciudadanos que determine la ley.

"Para el ingreso a una provincia ya constituida deberá realizarse una consulta popular en los municipios interesados.

"El departamento y los municipios aportarán a las provincias el porcentaje de sus ingresos corrientes que determinen la Asamblea y los concejos respectivos" - articulo 321.

Varios aspectos merecen comentario especial. En primer término se trata de entidades nuevas; por tanto, es menester entrar a constituirlas pues el constituyente renunció a la opción de predefinirlas.

En segundo lugar, no salta a primera vista cuál es su utilidad. Si se trataba de redefinir el mapa geopolítico del país, por cuanto hay una franja entre la delimitación jurídica de las entidades territoriales actualmente existentes y factores objetivos tales como cultura, desarrollo económico, geografía, etc., las provincias no serán de ninguna manera una solución por cuanto se deben trazar dentro del ámbito de los departamentos.

Desde el punto de vista funcional no tendrán ninguna atribución propia, pues todas han de ser delegadas por la nación o el departamento; por otro lado, los municipios que las integran podrán también proceder a la respectiva asignación.

Ahora bien, la ley que les otorgue competencias tiene un radio de acción muy limitado, pues debe en todo caso ceñirse a la Constitución, donde se procedió a repartir funciones, competencias y atribuciones a las entidades ya existentes, sin contar con la eventual institución de provincias o regiones.

En todo caso, parece que la asociación de municipios, mecanismo 
más ágil para cumplir el objetivo de prestación eficiente y eficaz de los servicios o de realización de obras públicas, en buena lógica administrativa ha de suplir siempre y en todo caso la provincia, evitándose de paso, una inflación de entidades territoriales, con adicionales costos burocráticos.

Es posible prever que seguramente los departamentos y municipios preferirán destinar sus recursos de manera temporal y para el cumplimiento de un objetivo específico, a través de una asociación, y no transferir sus aportes de manera permanentes, a una nueva entidad territorial.

\section{TERRITORIOS INDÍGENAS}

\section{Minorias y Estado pluralista}

Bajo la perspectiva de la geografía política, en la organización del poder territorial, han de tenerse en cuenta varios factores, como el grado de conflicto entre intereses personales y parciales, la coincidencia geográfica del Estado con la nación, el problema de las fronteras políticas y de las reivindicaciones territoriales de los grupos disidentes en el interior de un mismo Estado o de grupos afines que habitan en varios Estados distintos ${ }^{39}$.

Dentro de esta óptica, Norman POUNDS hace las siguientes aseveraciones: un Estado goza de mayor estabilidad cuando corresponde exactamente a la nación, pero un Estado en la realidad puede ser multinacional o al menos albergar varios grupos étnicos minoritarios, que a veces entran en conflicto.

En tales circunstancias el Estado debe construir una razón de ser que asegure el consenso de los grupos regionales, que tienen distintos ideales y motivos de asociación. En efecto, es meneșter actuar contra las fuerzas centrifugas, que bien pueden consistir en grandes distancias geográficas, precariedad de las vías de comunicación, distintas religiones, lenguas o culturas ${ }^{40}$.

Ahora bien, la solución no parece ser, estimular un proceso de absorción de la cultura minoritaria por parte de la mayoritaria, bajo muchos as-

39 Norman J. G. Pounds: Manuale di geografia politica, pp. 40-41, Franco Angeli Editore, Milano 1987.

40 Ibidem, pp. 42 y ss. 
pectos discutible. Se trata más bien de crear un adecuado marco político, un Estado pluralista, donde la tarea sea, según ZIPPELIUS, «hallar un compromiso susceptible de consenso entre intereses diversos, y ponderar aquellos que sean incompatibles». El autor agrega que se trata de un proceso democrático, fundado en el principio de autonomía, es decir, de la máxima participación de los interesados, donde las discusiones y los compromisos abiertos constituyen la forma legítima de regulación de intereses.

La sociedad pluralista concede a una multiplicidad de grupos concurrentes, la posibilidad de un desarrollo independiente, en el ámbito de una convivencia pacífica. Se trata de garantizar al mayor número de seres humanos el grado de desarrollo personal autónomo, que sea compatible con los intereses igualmente legítimos de sus conciudadanos.

El Estado pluralista introduce en el proceso político una multiplicidad de factores étnicos, económicos, religiosos e ideológicos, que de este modo obtienen la oportunidad de manifestarse políticamente ${ }^{41}$.

\section{El Estado pluralista en el texto constitucional de 1991 y los territorios indigenas}

Después de grandes debates en la Asamblea Nacional constituyente, que condujeron incluso a la amenaza de retiro de la representación indígena, la corporación decidió elevar a la categoría de entidad territorial de origen constitucional a los territorios indigenas. En líneas generales este reconocimiento encaja perfectamente dentro del nuevo marco supremo que prescribe como principio fundamental de los colombianos, el de la diversidad étnica y cultural -artículo $7 .^{\circ}$-, dentro de la concepción de un Estado pluralista.

Bajo la misma lógica, se consideran las lenguas y los dialectos de los grupos étnicos minoritarios, como oficiales del Estado, se autoriza la enseñanza bilingüe en estas comunidades -artículo 10-, se crea la circunscripción especial para la elección de senadores indígenas -artículo $171-$, se instituye la jurisdicción especial indígena $-246-$ y la posibilidad de participar en los ingresos corrientes de la nación, a la par de los municipios.

Respecto de los territorios indígenas, como entidad territorial -artículo 266-, es de anotar que su organización se atribuye al Congreso nacional, pues el artículo 329 recita: «... la conformación de las entidades

${ }^{41}$ Rehinolds ZIPPELIUS: Teoria del Estado, pp. 240-241, UNAM, México 1983. 
territoriales indígenas se hará con sujeción a lo dispuesto en la ley orgánica de ordenamiento territorial».

Igual sucede con el ámbito territorial de estas futuras entidades. Conforme a la norma citada, previo concepto de la comisión de ordenamiento territorial, al Gobierno nacional, con la participación de los representantes de las comunidades indigenas interesadas, corresponde tal potestad.

Por otro lado, los territorios indígenas que adopten el estatuto de entidad territorial, siguen siendo parte de las entidades departamentales o distritales a las que hoy están circunscritos. Se deberá, en todo caso, proceder a implementar, a través de la ley, el régimen de relaciones correspondientes, puesto que sobre un mismo espacio geográfico coexistirán entidades territoriales distintas.

El territorio indigena podrá desbordar las fronteras departamentales y la ley orgánica del ordenamiento territorial deberá prever esta hipótesis y establecer los mecanismos de administración y especificamente las relaciones entre los concejos indígenas y los respectivos gobernadores departamentales.

Es de subrayar que no todos los territorios indígenas podrán ser entidades territoriales; en tal caso, el respectivo territorio continuará sometido al régimen actual.

Los usos y las costumbres, naturalmente, desempeñarán un rol fundamental en su administración y gobierno, lo que evitará ulteriores procesos de aculturación, tan familiares al continente americano. En efecto, los usos y las costumbres reglamentarán el funcionamiento de los concejos.

Dentro de su marco territorial, son atribuciones de estas entidades: velar por la aplicación de las normas legales sobre uso del suelo y poblamiento; diseñar las políticas y los planes y programas de desarrollo económico y social, en armonia con el plan nacional de desarrollo; promover las inversiones públicas y velar por su debida ejecución; percibir y distribuir sus recursos; velar por la preservación de los recursos naturales; coordinar los programas y proyectos promovidos por las diferentes comunidades; colaborar en el mantenimiento del orden público de acuerdo con las instrucciones y disposiciones del Gobierno nacional -centralización del orden público--, representar a sus territorios ante el gobierno nacional y demás entidades a las cuales se integren y las que le señale la Constitución y la ley.

En fin, parece oportuno reportar el parágrafo donde se lee que la explotación de los recursos naturales en los territorios indigenas, se hará sin desmedro de la integridad cultural, social y económica de las comunida- 
des indígenas. En las decisiones sobre dicha explotación, el Gobierno propiciará la participación de los representantes de las respectivas comunidades.

\section{LAS REGIONES}

Otra gran controversia en el seno de la Asamblea Nacional constituyente, se presentó ante la propuesta de algunos constituyentes de introducir un Estado regional en Colombia. Dentro de sus abanderados se destacaron los constituyentes de la Costa Atlántica, quienes argumentaban que tradicionalmente han sido relegados por la Administración central, y que por tanto sus demandas nunca obtienen la adecuada respuesta.

Fue así como en el debate institucional, mucho se dijo sobre esa eventual entidad territorial y sobre la fisionomía que habria de tener el nuevo Estado.

Algunas consideraciones generales parecen oportunas, si se pretende entender a cabalidad la verdadera dimensión de la región introducida en la nueva constitución.

\section{El Estado regional: verdadero significado}

Recientemente, un defensor de este tipo de organización expresaba que el Estado regional es un ideal, un punto de encuentro entre el Estado unitario y el Estado federal, puesto que las exigencias de funcionalidad han demostrado el carácter dispersivo y poco eficiente de los modelos demasiado centralizados, que comportan, por lo demás, altos costos en la Administración y que propician las diferencias entre las áreas fuertes y débiles.

Es menester, por tanto tener en cuenta la identidad regional, de modo que las autoridades regionales respondan ante la comunidad que las ha elegido y luego ante la instancia superior. El mismo autor considera que un poder más cercano al ciudadano, está en grado de garantizar la efectividad de los derechos. En efecto, se debe privilegiar, siempre y en todo caso, la unidad menor - representativa de una problemática global y fragmentaria - , respecto de la grande, limitar el poder y estimular la participación ${ }^{42}$.

42 Giuliano Amato: op. cit., pp. 19-20. 
Justificado, a nivel teórico el regionalismo, es pertinente referirse a la naturaleza y estructura del Estado regional. Éste, al lado del Estado federal, es una de las formas más significativas de descentralización del poder político.

La doctrina tradicional, sin embargo, tiende a establecer diferencias tajantes entre el Estado regional y el Estado federal. Entre las más esgrimidas se cuenta la diferenciación con relación al origen histórico: el Estado federal surge de la agregación de Estados soberanos preexistentes; el estado regional es el resultado del reconocimiento de autonomía que hace un Estado unitario a sus entidades territoriales. En el primer caso, el poder circula de la periferia hacia el centro; en el segundo, del centro hacia la periferia.

Como consecuencia de lo anterior, y éste es el segundo criterio de diferenciación, la cláusula de residuo de competencias en los Estados federales se aplica a favor de los Estados miembros; en los regionales, todas aquellas competencias que no hayan sido atribuidas de manera taxativa a una entidad, corresponden al Estado central. Dentro de este esquema, los Estados miembros de una federación son titulares de soberanía, que se concreta, por lo demás, en la facultad de emanar normas constitucionales. La región, por el contrario, goza de un poder más limitado, que se denomina autonomía y se manifiesta en la potestad legislativa.

Por lo demás, y a diferencia de lo que sucede con la segunda Cámara federal que es representativa de los intereses de los Estados miembros, en el Estado regional las regiones carecen de tal instrumento.

En fin, los Estados federados tienen su propia organización para la administración de la justicia, situación ausente en las regiones, puesto que existe una rama única para todo el Estado regional, que actúa de manera desconcentrada.

Pero la práctica institucional tiende a desdibujar estas fronteras. Existen Estados unitarios que posteriormente han optado por el sistema federal, verbigracia Canadá o Venezuela. Paralelamente, y esto no se puede desconocer, el federalismo está viviendo un proceso de centralización a través de la fórmula del federalismo cooperativo; pero en casos más dramáticos, se trata tan sólo de una fórmula vaciada de contenido como en México o en la URSS. Encontramos por tanto casos específicos, donde el sentido de circulación del poder del centro hacia la periferia, o viceversa, se ha invertido, lo que priva de fundamento una diferenciación de los Estados regional y federal, a partir de ese primer criterio.

Respecto de la técnica de repartición de competencias, el sistema adoptado no siempre responde al paradigma del Estado federal. Hay Estados federales donde las competencias residuales se le atribuyen al Es- 
tado federal como se hizo a través del British North America Act de 1867, que contiene la lista de competencias del Estado federal y de los Estados miembros.

Estados regionales como el español, proceden a enumerar tanto las competencias regionales como las estatales -artículos 148 y 149 constitucionales-, y en Portugal, las competencias residuales se reconocen a favor de las regiones con autonomía especial, como por ejemplo a Madeira.

Que los Estados miembros de una federación no son soberanos, resulta del hecho de que éstos no son sujetos de derecho internacional. Pero tampoco a nivel interno se pueden considerar titulares de soberanía, puesto que su potestad constitucional se debe ejercer dentro de los marcos de la Constitución federal. Se acorta por tanto la distancia entre el poder constitucional del Estado miembro y la autonomía estatutaria de la región.

En materia de no representación de las regiones en la segunda Cámara, no se debe olvidar que en España, parte de los senadores los eligen las comunidades autónomas. En Italia, una reforma en tal sentido está presente con mucha fuerza en el debate institucional.

En materia de administración de justicia, existe una rama única para todo el Estado austríaco, que es federal; mientras que en Bélgica, las regiones tienen asiento en los órganos de administración.

Las anteriores consideraciones, reportadas por el profesor Giuseppe de VERGOTTINI ${ }^{43}$, permiten concluir que la diferencia entre un Estado regional y un Estado federal, no es de carácter ontológico, sino del grado de la autonomía reconocida al Estado miembro o a la región.

EI profesor VANDELLI, por su parte, afirma que no es inferior el grado de autonomía de una comunidad autónoma española como el País Vasco o Cataluña, al de un Länder austríaco ${ }^{44}$.

Esto ha dado lugar a formular nuevos calificativos para este tipo de Estado: federo-regional, regional federalizado, prefederal, etc.

\section{Tipos de regionalismo}

Antes de analizar los diferentes tipos de regionalismo que se han conocido en el mundo, es oportuno recordar que la región antes que una ca-

43 Diritto costituzionale comparato, pp. 281 y ss., Cedam, Padova 1987.

44 Luciano VANDELLI: Portere..., op. cit., p. 186. 
tegoría jurídica, es un dato sociológico, caracterizado por la existencia de una comunidad con religión, etnia, cultura, lengua, costumbres, que identifican sus miembros entre sí; esta comunidad, relativamente homogénea, habita en una zona geográfica con peculiaridades que la hacen distinta de las demás que integran un país.

Alrededor de este fenómeno han surgido diferentes esquemas jurídicos, en un primer momento, para racionalizar el proceso planificador; luego, para hacer más eficiente la Administración; en fin, para garantizar una adecuada entidad política al conglomerado allí residente.

Dentro de los esquemas organizacionales, encontramos el modelo de las estructuras estatales competentes en áreas regionales. Así, en Gran Bretaña, los ministros tienen asignadas responsabilidades en áreas regionales periféricas; por ejemplo, el secretario de Estado para el Ambiente tiene competencias especificas para las áreas metropolitanas; y para Gales, Escocia e Irlanda del Norte, se han nombrado específicos ministros, con competencia territorial. Los ejemplos antes mencionados responden nitidamente a un fenómeno de descentralización.

El segundo tipo lo encontramos a partir de la institución de las regiones administrativas, que carecen de legitimidad electoral. Así; en Turquía, las regiones han sido instituidas con fines de planificación.

En Francia hasta la ley 82-213 de 1982 -relativa a los derechos y las libertades de los municipios, departamentos y regiones-, que introdujo la región politica, existia la región planificadora. Se trataba de un ámbito territorial, donde debían operar órganos descentralizados del aparato central. Entre los años 55 y 60 , se instituyeron 21 regiones de esta naturaleza, y en 1970 se agregó Córcega.

Las funciones principales consistían en la preparación y el desarrollo del plan nacional. Estaban coordinadas por un prefecto y por una comisión de desarrollo regional, todos nombrados a nivel gubernamental.

El General de Gaulle en 1969 convocó a un referéndum para transformar estas regiones de planificación en entidades territoriales, pero el electorado no aprobó la propuesta. En 1972 se transformaron en establecimientos públicos - ley del 5 de julio-, y al lado de la función de preparación del plan nacional, se le atribuyeron algunas competencias de gestión administrativa; por tanto y paralelamente, la región fue dotada de propios, pero limitados recursos financieros. Para completar el esquema, se modificó la estructura, pues al lado del prefecto se creó un consejo regional, no electivo, formado por los diputados y los senadores de los departamentos respectivos y por los representantes designados por los álcaldes de los municipios y los consejeros departamentales, comprendidos en el ámbito de la región. Se creó, además, un comité económico y social. 
Pero este modelo de la región administrativa entró en crisis, junto con el del Estado centralista, y se hizo menester instituir la región política, donde sus autoridades fueran elegidas popularmente.

Nos encontramos ante el tercer modelo, cuyos ejemplos más paradigmáticos son el caso italiano ${ }^{45}$ y el español. Además de contar con autoridades elegidas popularmente, las regiones o comunidades autónomas gozan de potestad legislativa, con atribuciones de dirección política y participación en algunas funciones del Estado. Dentro de este nuevo tipo de Estado, se destaca el papel de la corte constitucional, como instancia de garantía de la esfera autonómica ${ }^{46}$.

\section{La región en la Constitución colombiana}

El nuevo texto, en el artículo 306, establece que dos o más departamentos podrán instituirse en regiones administrativas y de planificación, con personería jurídica, autonomía y patrimonio propios. Su objeto principal será el desarrollo económico del respectivo territorio.

Es decir que se trata del segundo tipo de region: administrativa y de planificación, al igual que la existente en Francia a partir de los años cincuenta y cinco. Posiblemente en el desarrollo legislativo se le otorgue a ésta, el carácter de establecimiento público, forma jurídica que precisamente goza de personería jurídica, autonomía administrativa y patrimonio propios, tal como ló dispone la Constitución.

Sin embargo, el mismo texto constitucional establece las bases para que la región se transforme en entidad territorial, por mandato de la ley -artículo 286-. En efecto, y a tenor del artículo 307, la respectiva ley orgánica, previo concepto de la comisión de ordenamiento territorial, establecerá las condiciones para la conversión de la región en entidad territorial. La decisión del Congreso se someterá a referéndum de los ciudadanos interesados.

Se trata, pues, de un procedimiento rígido, que encontrará múltiples obstáculos para llegar a su culminación. En todo caso, si en un futuro la región llega a ser entidad territorial, dentro del actual marco constitucional no se podrá clasificar dentro de la categoria de región política, pues

45 Las regiones aparecen en la Constitución italiana de 1948, pero su «atuazione", es decir su desarrollo legal e implementación, se hacen realidad sólo a partir de la década de los setenta.

${ }_{46}$ En Giuseppe DE VergotTINI: Diritto..., op. cit. En Francia las regiones no tienen potestad legislativa ni origen constitucional. 
hemos ya visto cuán limitado es el marco de la autonomía, reconocido en el artículo 287 del nuevo texto para las entidades territoriales.

Se tratará sí de una región muy similar a la actualmente existente en el ordenamiento francés, de origen legal y sin potestad legislativa.

Respecto de este último punto, es desde ya previsible, un gran debate sobre la potestad estatutaria a que hace referencia el inciso 2 del artículo 307, pues entendida en su sentido genuino, tal atribución es de tipo legislativo, pero en el caso colombiano, ha sido sometida a los parámetros legislativos que para el efecto promulgue el Congreso nacional, único legislador.

En fin, el otro gran problema se plantea con relación a los recursos que ha de establecer la ley, aunque de manera expresa se haya reservado a nivel constitucional, una notable fuente de ingresos: su participación en los fondos provenientes del fondo nacional de regalías.

Un eventual proceso de regionalización del pais podria contribuir a redefinir el mapa geopolítico nacional en términos más funcionales para la planeación y más representativos de los intereses locales, garantizando un marco adecuado para un Estado pluralista. Sin embargo tal posibilidad parece bastante utópica, frente a un departamento tan fortalecido, que en ningún momento pretenderá abandonar su posición de privilegio, en la pirámide administrativa actual, para proceder a fusionarse con otros, en regiones. 